\title{
The association between natural outdoor environments and common somatic symptoms
}

Authors

C. Watsonabcd, M.J. Nieuwenhuijsenabc, M. Triguero-Mase, M. Cirachabc, J. Maas ${ }^{f}$, C. Gidlowf, H. Kruizei, S. Andrusaitytej, R. Grazulevicienej, W.L. Zijlemaabc

Affiliations

a Barcelona Institute for Global Health (ISGlobal), Doctor Aiguader 88, 08003 Barcelona, Spain

b Universitat Pompeu Fabra (UPF), Doctor Aiguader 88, 08003 Barcelona, Spain

c CIBER Epidemiología y Salud Pública (CIBERESP), Melchor Fernández Almagro, 35, 28029 Madrid, Spain

d Maastricht University, Minderbroedersberg 4-6, 6211 LK Maastricht, The Netherlands

e Universitat Autònoma de Barcelona (UAB); Barcelona Lab for Urban Environmental Justice and Sustainability; Institute for Environmental Science and Technology (ICTA); Medical Research Institute (IMIM), Hospital del Mar, Barcelona, Spain

f Department of Clinical Psychology, Vrije Universiteit Amsterdam, Van der Boechorstraat 1, 1081 BT Amsterdam, Netherlands

h Centre for Health and Development, Staffordshire University, Leek Road, Stokeon-Trent, ST4 2DF, United Kingdom

' Center for Sustainability, Environment and Health, National Institute for Public Health and the Environment (RIVM), Antonie van Leeuwenhoeklaan 9, $3721 \mathrm{MA}$ Bilthoven, The Netherlands

j Department of Environmental Sciences, Vytautas Magnus University, K. Donelaicio str. 58, 44248 Kaunas, Lithuania

Corresponding author

Wilma L Zijlema PhD

Barcelona Institute for Global Health (ISGlobal)

Barcelona Biomedical Research Park (PRBB)

Doctor Aiguader 88, 08003 Barcelona, Spain

Tel: +34 932147300, Fax: +34 9321473 02, E-mail: wilma.zijlema@isglobal.org

Funding

The research leading to these results has received funding from the European Community's Seventh Framework Programme (FP7/2007-2013) under grant agreement no 282996. W.L. Zijlema is supported by a Sara Borrell grant from the Instituto de Salud Carlos III (CD17/00195). We acknowledge support from the Spanish Ministry of Science and Innovation through the "Centro de Excelencia Severo Ochoa 2019-2023" Program (CEX2018-000806-S), and support from the Generalitat de Catalunya through the CERCA Program (ISGlobal). 



\title{
The association between natural outdoor environments and common somatic symptoms
}

\begin{abstract}
There is growing evidence that urban natural outdoor environments (NOE) may positively impact health by reducing stress and stress-related symptoms. However, there is limited research investigating this link across a range of NOE indicators. This cross-sectional study investigated the association between neighbourhood NOE (availability, use, and satisfaction with NOE) and common somatic symptoms and the role of potential mediators. Data were analysed from 3481 adults from Barcelona (Spain), Doetinchem (Netherlands), Kaunas (Lithuania) and Stoke-on-Trent (United Kingdom). NOE data were obtained through selfreported data and environmental measurements. Common somatic symptom data were selfreported. Mixed effects regression models were used for analysis, with models adjusted for potential sociodemographic confounders. Higher satisfaction with neighbourhood NOE was associated with lower prevalence of common somatic symptoms $(\exp (\beta) 0.97 ; 95 \%$ CI 0.96 , 0.98); an association partially mediated by mental health, social cohesion and air quality concern. A longer time spent in NOE was associated with lower prevalence of common somatic symptoms in low socioeconomic status neighbourhoods $(\exp (\beta) 0.98 ; 95 \%$ CI $0.96,1.00)$. A higher number of neighbourhood green spaces (300m buffer) was associated with higher prevalence of common somatic symptoms $(\exp (\beta) 1.03 ; 95 \%$ CI $1.00,1.05)$. No statistically significant associations were found for other NOE indicators. Study findings suggest that higher satisfaction with NOE may be associated with lower prevalence of common somatic symptoms, with mental health, social cohesion and concern about air quality playing partial mediating roles. Little evidence was found of an association between objective NOE measurements and common somatic symptoms, underlining the importance of perceptions of NOE for conferring health benefits.
\end{abstract}

Keywords: common somatic symptoms; natural outdoor environments; stress; stressrelated symptoms; green space; nature perception 


\section{Introduction}

Over half of the global population now lives in urban areas compared to $30 \%$ of the population in 1950 (United Nations - Department of Economic and Social Affairs - Population Division, 2018). By 2050, these levels are expected to have risen even further, to almost $70 \%$ of the global population (United Nations - Department of Economic and Social Affairs - Population Division, 2018). While urban living can have benefits for health and wellbeing, including improved access to healthcare and opportunities for social connection (Sanz-Barbero et al., 2012; Turnbull et al., 2008), environmental and social stressors such as traffic, crime and high levels of pollution, can make towns and cities challenging environments in which to live. There is a growing body of evidence linking such environments with a range of health conditions and risk factors, including higher levels of stress and stress-related symptoms (Gong et al., 2016; Lachowycz and Jones, 2011; Roe et al., 2013; Won et al., 2016).

Stress can manifest both as psychological and physical symptoms, including common somatic symptoms (Lipowski, 1988). Common somatic symptoms are those that may or may not have a conclusive organic basis and include sensations such as pain, nausea and fatigue (Zijlema et al., 2013). These symptoms are prevalent across the general population but the tendency to experience and seek help for them is particularly common among those suffering from stress and associated psychological conditions, as well as those with certain personality traits (de Waal et al., 2004; Lipowski, 1988; Rosmalen et al., 2007). Persistent symptoms can have a considerable impact on the lives of individuals, affecting both employment and social functioning (Gureje et al., 1997; Rask et al., 2015; Terluin et al., 2011). Beyond the human costs, common somatic symptoms also place a substantial burden on the healthcare system due to a high use of medical resources (Barsky et al., 2005).

It has been suggested that incorporating natural outdoor environments (NOE), such as parks and lakes, into the design of urban areas may help to reduce stress and promote mental wellbeing (Nieuwenhuijsen et al., 2016). Previous studies have linked exposure to these spaces with lower perceived and physiological stress levels and improved stress recovery (Ewert and Chang, 2018; Tyrväinen et al., 2014; Ulrich et al., 1991). The mechanisms through which these benefits occur are not yet fully understood but four key pathways are thought to play important roles (Hartig et al., 2014). Firstly, it has been proposed that NOE may promote physical activity by providing space for activities such as walking and cycling, and may enhance positive social contact by providing areas to interact with others (Hartig et 
al., 2014). These spaces are also thought to reduce exposure to harmful pollutants and provide a restorative environment away from everyday stressors (Hartig et al., 2014; Kaplan, 1995; Ulrich et al., 1991). While the benefits of physical activity and social contact are derived from actively spending time in $\mathrm{NOE}$, the latter two pathways may influence health simply through the presence of NOE within a neighbourhood (e.g. by providing a green/blue view that can be seen through the windows of the home) (Hartig et al., 2014).

Previous studies investigating the link between neighbourhood NOE and common somatic symptoms have often reported a small but statistically significant negative association (Groenewegen et al., 2018; Korpela and Ylen, 2007; Maas et al., 2009; Triguero-Mas et al., 2017; van den Berg et al., 2010). For example, a Dutch study using electronic GP records found a lower prevalence of common somatic symptoms among those living in areas with a higher percentage of green space (Maas et al., 2009). A recent study by Triguero-Mas et al., which used smartphones to collect data on time spent in NOE, reported a statistically significant negative association between time spent in surrounding greenness and common somatic symptoms (Triguero-Mas et al., 2017). Other studies have found no statistically significant association between NOE exposure and common somatic symptoms (Piccininni et al., 2018; Zock et al., 2018). Several of the studies that reported a statistically significant relationship between NOE and common somatic symptoms found that this relationship varied according to sociodemographic characteristics. For instance, stratified analysis undertaken by Groenewegen et al. revealed a statistically significant association between green space and somatic symptoms for the lowest quintile of socioeconomic status (SES) only, with more green space associated with fewer somatic symptoms; a finding also supported by Maas et al. (Groenewegen et al., 2018; Maas et al., 2009). Triguero Mas et al. found stronger relationships between somatisation and contact with surrounding greenness among men, younger participants and those with a low-medium education level, as well as some differences between participants from different cities (Triguero-Mas et al., 2017).- To date, few studies have investigated the potential mechanisms through which NOE and common somatic symptoms may be associated. Those that have indicate that stressreduction and social cohesion may play particularly important roles (de Vries et al., 2013; Triguero-Mas et al., 2017). Triguero-Mas et al. (2017) found that perceived stress completely mediated the relationship between contact with NOE and the lack of somatisation. Since they could not establish mediation by physical activity, they argued that it might not be the intensity of activity undertaken in a NOE that is of importance to health, 
but the stress reduction that visiting the NOE provokes (Triguero-Mas et al., 2017). This was also concluded by de Vries et al. (2013), that found that especially stress reduction and social cohesion were important mediators of the association between NOE and perceived general health and acute health complaints (de Vries et al., 2013).

Further studies are needed to investigate whether the findings from existing research hold true in other settings and to develop further detail on the potential mechanisms through which associations may occur. Previous studies generally use only one type of NOE measurement (most commonly amount of green space or self-reported use of green space) and have rarely explored individual perceptions of NOE_(Frumkin et al., 2017; Markevych et al., 2017; Nieuwenhuijsen et al., 2016). Examining a range of objective and subjective NOE indicators in one study, covering both NOE availability and contact, would help to provide important additional detail required for policy-making. For example, knowing whether individuals need to spend time in neighbourhood NOE to see positive health effects would help to determine whether the introduction of more neighbourhood NOE should be accompanied by interventions that actively encourage its use. Knowing whether positive perceptions of NOE are necessary for health benefits may help to inform community involvement processes during the development of new green spaces.

The aim of this study was to investigate the association between neighbourhood NOE exposure and common somatic symptoms in a sample from four European cities. Specifically, the study sought to address whether there is an association between (objective and subjective) availability of, satisfaction with, and time in NOE, and common somatic symptoms; and whether these associations are mediated by perceived mental health, social cohesion, outdoor physical activity and/or air quality concerns. We hypothesised that higher levels of neighbourhood NOE availability, time spent in NOE, and levels of satisfaction with NOE would be associated with fewer common somatic symptoms, and that perceived mental health, social cohesion, outdoor physical activity and air quality concerns, (that are indicators of the four potential pathways linking NOE and health) would play mediating roles.

\section{Methods}

\subsection{Study Setting and Data Collection}


This cross-sectional study analysed data from the Positive Health Effects of the Natural Outdoor environment in Typical Populations in different regions in Europe (PHENOTYPE) project. Respondents were randomly selected from approximately 30 neighbourhoods across four European cities: Barcelona (Spain), Doetinchem (Netherlands), Kaunas (Lithuania) and Stoke-on-Trent (United Kingdom; UK)_(Figure 1). Diverse neighbourhoods were selected to obtain variation in SES and availability of NOE. Data were collected between May and November 2013 through an interview-administered questionnaire (except in Kaunas where a self-administered questionnaire was used). Further detail relating to study methods can be found in the PHENOTYPE study protocol (Nieuwenhuijsen et al., 2014) and elsewhere (Kruize et al., 2019; Smith et al., 2017). Ethical clearance was obtained by the principal investigators of the PHENOTYPE study in every city in which the study was conducted. All study participants provided written informed consent before taking part. The study was conducted in accordance with the Declaration of Helsinki (World Medical Association, 2013).

\subsection{Study Population}

Approximately 1000 residents per city, and 30 per neighbourhood $(n=3986)$, aged 18 to 75 years old were recruited for the study. Data from 505 respondents were excluded from the current analysis due to missing values for common somatic symptoms, perceived residential greenness/blueness, time spent in NOE, age, gender, education level, perceived income, SES, employment status, household composition, smoking status or dog ownership. A final sample of 3481 was included in analysis.

\section{$2.3 \quad$ Study Data}

\subsubsection{NOE exposure}

Natural outdoor environments were considered to include natural green spaces such as nature reserves, forests, parkland, roof gardens and city parks, and natural blue spaces, including canals, ponds, creeks, rivers and beaches (Nieuwenhuijsen et al., 2014).

\subsubsection{Objective neighbourhood NOE availability}


Residential surrounding greenness: Residential surrounding greenness was measured using the Normalised Difference Vegetation Index (NDVI), which is a measure of greenness. NDVI makes use of differences in the portion of visible light and near infrared light reflected by the surface of healthy and sparse vegetation (Weier and Herring, 2000). It is measured on a scale between -1 and +1 , with higher values indicating higher levels of green vegetation. NDVI values were derived from Landsat 8 satellite images with $30 \mathrm{~m} \times 30 \mathrm{~m}$ resolution (Smith et al., 2017). Mean NDVI values within a $100 \mathrm{~m}, 300 \mathrm{~m}$ and $500 \mathrm{~m}$ circular buffer were calculated for each residence and rescaled according to city-specific interquartile ranges in order to compare common somatic symptoms in an area with typical low (25th percentile) mean NDVI with an area with typical high ( $75^{\text {th }}$ percentile) mean NDVI. This exposure indicator is meant to provide a measure of average greenness of the area around the residence.

Number of natural spaces: The number of natural spaces within a $300 \mathrm{~m}$ and $500 \mathrm{~m}$ network buffer was calculated using a modified road network for each residence in Barcelona, Stokeon-Trent and Kaunas using Urban Atlas 2006, which provides reliable and comparable urban land use maps. The categories of natural space included were (a) green urban areas; (b) agricultural and semi natural areas; (c) forests and (d) water bodies. For Doetinchem, comparable categories were defined using the 'TOP10NL' database as Urban Atlas data were not available. A natural space was included in the count if it intersected or was within the residential network buffer (Smith et al., 2017). The minimum size of natural space included was $\geq 0.25$ ha due to the spatial resolution of Urban Atlas (Smith et al., 2017). Variables were analysed as continuous count data. This exposure indicator is meant to provide a measure of access to natural spaces.

Distance to nearest natural space: Straight-line distance (in metres) to the nearest natural space was calculated for each respondent using Urban Atlas 2006 for Barcelona, Stoke-onTrent and Kaunas, and the 'Top10 nlTOP10NL' database for Doetinchem. The categories of natural space included were (a) green urban areas; (b) agricultural and semi-natural areas; (c) forests; and (d) water bodies (Smith et al., 2017). This exposure indicator is meant to provide a measure of access to natural spaces. 


\subsubsection{Subjective NOE availability, visits, and satisfaction}

Perceived residential greenness/blueness: Respondents were asked to describe their (a) street, (b) neighbourhood, and (c) the view from their home in terms of green and blue. Each question was answered on a 5-point response scale, ranging from "not at all" to "very". A sum score was calculated with higher scores representing higher perceived residential greenness/blueness.

Time spent in NOE: Respondents were asked two questions to assess time spent in NOE near home: "how often did you visit a green/blue environment near your home in the last 4 weeks?" (assessed on 5-point scale from "never" to "(almost) daily"); and "how much time did you spend at a green/blue environment close to home in the last 4 weeks?" (assessed on 5 -point scale from " $<1$ hour" to "6-10 hours"). An area close to home was defined as a location less than 15 minutes by bike/foot from home. These responses were used to calculate a composite score representing the total amount of time (frequency $\mathrm{x}$ average duration) spent in a NOE near home. As response scales were categorical, mid-point values from each response option were taken to calculate the composite variable. Values were rescaled using city-specific interquartile ranges in order to compare common somatic symptoms between a person with typical low ( $25^{\text {th }}$ percentile) and typical high ( $75^{\text {th }}$ percentile) time spent in NOE.

Satisfaction with NOE: Respondents were asked to rate their satisfaction with the quality, amount, safety and maintenance of the green/blue environment in their neighbourhood. Each item was assessed on a 5-point scale from "very dissatisfied" to "very satisfied". A sum score (4-20) was calculated with higher scores representing higher levels of satisfaction.

\subsubsection{Common somatic symptoms}

The presence of common somatic symptoms was measured with a 9-item question, using 7 items from the Four-Dimensional Symptom Questionnaire (4DSQ) somatisation/distress scale plus two additional items (Terluin et al., 2006; Triguero-Mas et al., 2017). Respondents were asked to assess whether they had experienced any of the following symptoms in the past week: (i) dizziness/light-headed, (ii) painful muscles, (iii) back and/or shoulder pain, (iv) headache, ( $v$ ) nausea, (vi) pain in the abdomen or stomach area, (vii) pain in the chest, (viii) ache in the back of the head, (ix) fatigue. Each item was answered on a 5-point scale ranging 
from "no" to "very often". Items were transformed into dichotomous variables "no" (those who answered "no" only) or "yes" (sometimes; regularly; often; very often) and combined into a symptom count from 0 to 9 .

\subsubsection{Mediators}

Mental Health: Perceived mental health was assessed using a subscale of the Short Form Health Survey (SF-36), which has been shown to be reliable and valid (Ware and Sherbourne, 1992). The subscale comprises five items relating to aspects of mental health (e.g. depression) during the past 4 weeks, answered on a 6-point scale ranging from "none of the time" to "all of the time". Where responses to one or two items from the scale were missing, values were replaced with an average of the other items. Where more than two items from the scale were missing, these observations were excluded from analysis. According to guidelines, a sum score was calculated and transformed into a scale from 0 to 100, with higher scores indicating better perceived mental health (Ware and Sherbourne, 1992).

Social Cohesion: Social cohesion in the neighbourhood was assessed using the 5 -item social cohesion and trust scale developed by Sampson et al., (Sampson et al., 1997). Scale items relate to interactions between people within a neighbourhood (e.g. levels of trust and willingness to help others). A sum score (5-25) was calculated with a higher score indicating more social cohesion.

Outdoor Physical Activity: Outdoor physical activity was assessed using items from the Short Questionnaire to Assess Health enhancing physical activity (SQUASH) survey (van Poppel et al., 2010; Wendel-Vos et al., 2003). Respondents were asked how often (days/week) and how long on average (minutes) they: walk or bike to school or work; walk, bike or garden during leisure time; and participate in sports. These items were considered the most likely to take place outdoors (and potentially in NOE) and therefore most relevant for analysis. Responses to the questions were used to calculate a composite score (frequency $x$ average duration) representing the total amount of time conducting outdoor physical activity per week.

Air Quality Concern: Air quality concern was assessed by asking "are you worried that the air pollution in your neighbourhood can lead to health problems?", with answers on a 10-point 
scale ranging from "not at all worried" to "extremely worried". Scores were transformed into four categories (not at all worried; a little worried; worried; severely worried) according to cut-offs previously defined for noise annoyance (Miedema and Oudshoorn, 2001) and dichotomised into "high concern" (worried; severely worried) and "low concern" (not at all worried; a little worried).

\subsubsection{Other Covariates}

Analyses were adjusted for the following sociodemographic characteristics (selected based on previous studies (Maas et al., 2009; White et al., 2017; Zijlema et al., 2018) and theoretical plausibility of potential confounding): age, gender, education level (primary school; secondary school; university degree or higher), perceived income (cannot make ends meet; enough to get along; comfortable), employment status (employed; not employed) neighbourhood SES (low; medium; high; based on country-specific income and education level data, see (Ruijsbroek et al., 2017)), and city. Analyses were further adjusted for smoking status (yes; used to smoke; have never smoked), household composition (alone; with partner only; with children younger than 12 years old; with children older than 12 years old only), and dog ownership (yes; no).

\subsection{Statistical Analysis}

Associations between common somatic symptoms and NOE indicators were analysed using mixed effects negative binomial regression models, with a random intercept at the neighbourhood level. This approach was selected because of overdispersion of the data (i.e. variance greater than the mean) and following comparison of Akaike Information Criterion (AIC) values across models to evaluate model fit (Supplementary Material, Table S1) and consultation of literature relevant to analysis of symptom count data (Xu et al., 2017; Zaninotto and Falaschetti, 2011). Negative binomial model regression coefficients are usually exponentiated and reported as Incidence Rate Ratios. However, given this study's crosssectional nature, reporting an incidence is not appropriate. The coefficients in this study are therefore referred to as exponentiated regression coefficients $(\exp (\beta))$, representing the proportional increase/decrease in common somatic symptom count. Crude and adjusted models were constructed, with the latter adjusted for city and the covariates outlined in section 2.3.4. Where crude and adjusted models produced substantially different results, the 
relative importance of potential confounders was further investigated by excluding significant confounders individually from the adjusted model. The statistical significance of interaction terms for city, gender, income, SES and employment status was assessed using likelihood ratio tests, and significant interactions (city, gender and SES) were investigated further through sub-group analysis.

Mediation analysis was conducted according to the Baron \& Kenny method (Baron and Kenny, 1986), taking into account critiques by Zhao et al., (2010) (Zhao et al., 2010). Indirect pathways between NOE indicators and common somatic symptoms were investigated by analysing the association between NOE indicators and potential mediators, and between potential mediators and common somatic symptoms, adjusted for NOE indicator. Overall pathways were then studied by investigating the association between NOE indicators and common somatic symptoms, adjusted for potential mediators. Linear regression (mental health and social cohesion), negative binomial regression (outdoor physical activity) and logistic regression (air quality concern) were used to analyse the association between NOE indicators and potential mediators. Negative binomial regression models were used in all other mediation analyses. Associations with $p$-value $\leq 0.05$ were considered statistically significant. All analyses were conducted using Stata 14.2.

\subsection{Sensitivity Analysis}

Associations between all NOE indicators (objective and subjective) and common somatic symptoms were repeated excluding respondents with one or more chronic disease and, separately, excluding respondents with restricted mobility, to reduce the likelihood that symptoms related to an established medical condition were captured within the common somatic symptom score. In addition, the main analyses were additionally adjusted for having a chronic disease and having restricted mobility as an alternative way to assess the influence of an established medical condition on common somatic symptoms. The main analyses were also repeated with each individual somatic symptom excluded (one at a time) from the total common somatic symptom score in order to test the influence of each symptom on the overall patterns of association. Associations between all NOE indicators and common somatic symptoms were repeated with a dichotomous outcome variable (reporting any of the 9 symptoms; no symptoms) using mixed effects logistic regression models, with a random intercept at the neighbourhood level. 
Sensitivity analyses were also used to further investigate observed statistically significant associations between NOE indicators and common somatic symptoms. The association between the number of green spaces within a $300 \mathrm{~m}$ buffer and common somatic symptoms was further studied by rescaling the variable using city-specific interquartile ranges in order to compare common somatic symptoms between a person in an area with a typical low ( $25^{\text {th }}$ percentile) and typical high ( $75^{\text {th }}$ percentile) number of green spaces. The influence of individual cities on these associations was tested by excluding each city individually from analysis.

\section{Results}

\subsection{Population Characteristics}

Respondents had a mean age of 51.6 years old (SD 15.8 ) and $54.8 \%$ were female (Table 1 ). There were statistically significant differences between cities for each of the parameters studied. The median number of common somatic symptoms reported by respondents in the week prior to the survey was 2 (IQR 3), with $24.6 \%$ of respondents reporting no somatic symptoms. The median number of reported symptoms was higher in Doetinchem and Kaunas than in Barcelona and Stoke-on-Trent. The smallest median distance (46.1 metres) to the nearest natural space was in Doetinchem, and the largest median distance (300.5 metres) was in Barcelona. Median length of time spent in NOE was highest in Doetinchem (10hrs/4 weeks) and lowest in Stoke-on-Trent (1.25hrs/4 weeks). Median level of satisfaction with NOE was highest in Doetinchem and Stoke-on-Trent and lowest in Barcelona and Kaunas (Table 2).

Table 1. Demographics of the study population - pooled and city-specific analyses

\begin{tabular}{|c|c|c|c|c|c|c|}
\hline & Pooled & Barcelona & Doetinchem & Kaunas & Stoke-on-Trent & \\
\hline Participants, n (\%) & $3481(100)$ & $970(27.9)$ & $843(24.2)$ & $817(23.5)$ & $851(24.5)$ & \\
\hline Age, mean (SD) & $51.6(15.8)$ & $45.18(15.5)$ & $56.40(12.1)$ & $60.10(13.6)$ & $45.99(16.0)$ & $*$ \\
\hline Gender & & & & & & $*$ \\
\hline Female, $n(\%)$ & $1908(54.8)$ & $507(52.3)$ & $474(56.2)$ & $489(59.9)$ & $438(51.5)$ & \\
\hline Education level & & & & & & $*$ \\
\hline Low, $n(\%)$ & $246(7.07)$ & $143(14.7)$ & $10(1.84)$ & $15(1.84)$ & $78(9.17)$ & \\
\hline Medium, $n(\%)$ & $1526(43.8)$ & $375(38.7)$ & $395(46.9)$ & $209(25.6)$ & $547(64.3)$ & \\
\hline High, $n(\%)$ & $1709(49.1)$ & $452(46.6)$ & $438(52.0)$ & $593(72.6)$ & $226(26.6)$ & \\
\hline
\end{tabular}




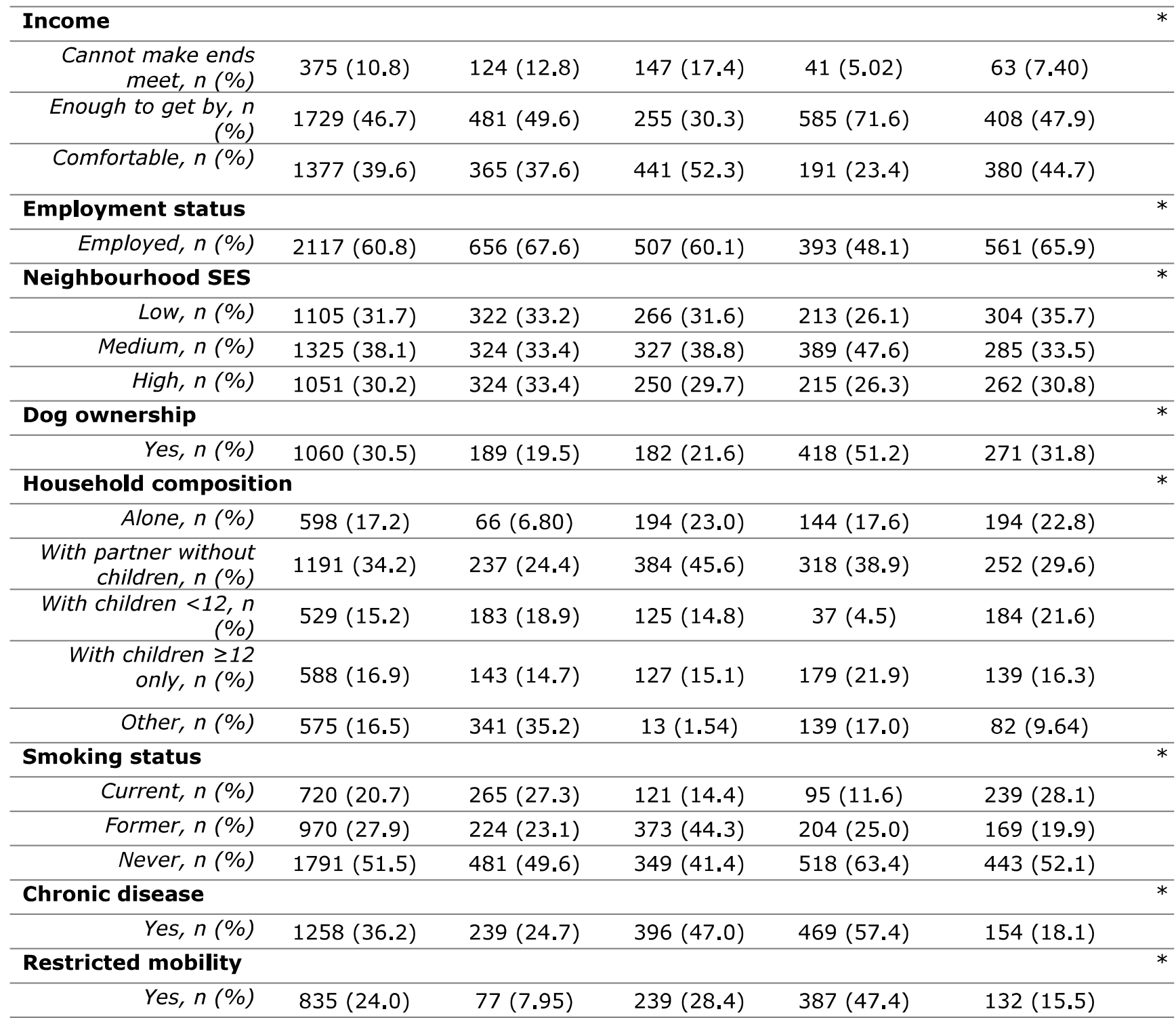

$n$, number of participants; SD, standard deviation; SES, socioeconomic status. *statistically significant difference between cities at $5 \%$ level based on chi-squared and one-way Analysis of Variance (ANOVA) tests

Table 2. NOE exposure and common somatic symptoms among study population pooled and city-specific analyses

\begin{tabular}{|c|c|c|c|c|c|c|}
\hline & Pooled & Barcelona & Doetinchem & Kaunas & $\begin{array}{c}\text { Stoke-on- } \\
\text { Trent }\end{array}$ & \\
\hline \multicolumn{7}{|c|}{ Exposure (objective indicators) } \\
\hline $\begin{array}{r}\text { Median (IQR) residential } \\
\text { surrounding greenness - } \\
100 \mathrm{~m} \text { buffer }(0-1)\end{array}$ & $\begin{array}{c}0.46 \\
(0.25)\end{array}$ & $0.18(0.11)$ & $0.52(0.15)$ & $\begin{array}{c}0.56 \\
(0.10)\end{array}$ & $0.45(0.10)$ & $*$ \\
\hline
\end{tabular}




\begin{tabular}{|c|c|c|c|c|c|c|}
\hline $\begin{array}{l}\text { Median (IQR) residential } \\
\text { surrounding greenness - } \\
300 \mathrm{~m} \text { buffer }(0-1)\end{array}$ & $\begin{array}{l}0.48 \\
(0.24)\end{array}$ & $0.19(0.09)$ & $0.54(0.12)$ & $\begin{array}{l}0.55 \\
(0.10)\end{array}$ & $0.48(0.10)$ & $*$ \\
\hline $\begin{array}{r}\text { Median (IQR) residential } \\
\text { surrounding greenness - } \\
500 \mathrm{~m} \text { buffer }(0-1)\end{array}$ & $\begin{array}{l}0.50 \\
(0.25)\end{array}$ & $0.20(0.07)$ & $0.55(0.10)$ & $\begin{array}{l}0.55 \\
(0.09)\end{array}$ & $0.48(0.11)$ & $*$ \\
\hline $\begin{array}{r}\text { Median (IQR) number of } \\
\text { natural spaces - 300m buffer } \\
(0-15)\end{array}$ & $1(2)$ & $0(1)$ & $3(3)$ & $1(1)$ & $1(1)$ & $*$ \\
\hline $\begin{array}{r}\text { Median (IQR) number of } \\
\text { natural spaces - 500m buffer } \\
(0-19)\end{array}$ & $3(4)$ & $1(3)$ & $6(3)$ & $2(2)$ & $3(2)$ & $*$ \\
\hline $\begin{array}{l}\text { Median (IQR) distance to } \\
\text { nearest natural space }(\mathrm{m})\end{array}$ & $\begin{array}{c}111.8 \\
(184.2)\end{array}$ & $\begin{array}{l}300.5 \\
(338.5)\end{array}$ & $\begin{array}{c}46.1 \\
(85.9)\end{array}$ & $\begin{array}{c}114.6 \\
(165.9)\end{array}$ & $\begin{array}{c}91.1 \\
(105.0)\end{array}$ & * \\
\hline \multicolumn{7}{|c|}{ Exposure (subjective indicators) } \\
\hline $\begin{array}{r}\text { Median (IQR) perceived } \\
\text { residential } \\
\text { greenness/blueness } \\
(\text { sum score } 0-12)\end{array}$ & $7(5)$ & $5(6)$ & $9(3)$ & $8(3)$ & $7(5)$ & * \\
\hline $\begin{array}{r}\text { Median (IQR) Time spent in } \\
\text { NOE near home } \\
\text { (hours/4 weeks) }\end{array}$ & $4(11.8)$ & $4(12)$ & $10(8.25)$ & $4(11.3)$ & $1.25(10)$ & * \\
\hline $\begin{array}{r}\text { Median (IQR) satisfaction with } \\
\text { NOE (sum score } 4-20 \text { ) }\end{array}$ & $15(4)$ & $14(5)$ & $16(3)$ & $14(4)$ & $16(4)$ & $*$ \\
\hline \multicolumn{7}{|l|}{ Outcome } \\
\hline $\begin{array}{l}\text { Median (IQR) number of } \\
\text { somatic symptoms }(0-9)\end{array}$ & $2(3)$ & $1(3)$ & $3(3)$ & $3(3)$ & $1(3)$ & $*$ \\
\hline $\begin{array}{l}\text { Respondents reporting no } \\
\text { somatic symptoms, n (\%) }\end{array}$ & $\begin{array}{c}857 \\
(24.6)\end{array}$ & $\begin{array}{c}345 \\
(35.6) \\
\end{array}$ & $\begin{array}{c}94 \\
(11.2)\end{array}$ & $\begin{array}{c}53 \\
(6.49) \\
\end{array}$ & 365 (42.9) & $*$ \\
\hline \multicolumn{7}{|l|}{ Mediators } \\
\hline $\begin{array}{r}\text { Median (IQR) Mental Health } \\
\text { Score (0-100) } \\
\text { (higher=better mental health) }\end{array}$ & $76(24)$ & $72(24)$ & $84(12)$ & $72(24)$ & $76(20)$ & $*$ \\
\hline $\begin{array}{r}\text { Median (IQR) Social Cohesion } \\
\text { Score }(5-25) \\
\text { (higher=more cohesion) }\end{array}$ & $17(5)$ & $17(4)$ & $19(4)$ & $15(4)$ & $18(4)$ & $*$ \\
\hline $\begin{array}{r}\text { Median (IQR) Outdoor } \\
\text { Physical Activity } \\
\text { (minutes per week) }\end{array}$ & $\begin{array}{l}390 \\
(600)\end{array}$ & $\begin{array}{c}263 \\
(445)\end{array}$ & $\begin{array}{c}600 \\
(490)\end{array}$ & $\begin{array}{c}540 \\
(660)\end{array}$ & $\begin{array}{c}140 \\
(420)\end{array}$ & * \\
\hline $\begin{array}{r}\text { High level of concern about } \\
\text { air quality, } n(\%)\end{array}$ & $\begin{array}{c}1180 \\
(33.9)\end{array}$ & $\begin{array}{c}668 \\
(68.9)\end{array}$ & $\begin{array}{c}125 \\
(14.8)\end{array}$ & $\begin{array}{c}259 \\
(31.7)\end{array}$ & $128(15.0)$ & * \\
\hline
\end{tabular}

$n$, number of participants; NOE, natural outdoor environment; IQR, interquartile range. *statistically significant difference between cities at $5 \%$ level based on chi-squared and Kruskal-Wallis tests

\subsection{Correlation between NOE indicators}

In general, the correlations between different objective NOE exposure indicators were stronger than between objective and subjective NOE indicators. Between objective NOE 
indicators, residential surrounding greenness correlated more strongly with distance to nearest natural space than number of natural spaces. Between subjective NOE indicators, there was a moderate correlation between perceived residential greenness/blueness and satisfaction with NOE. Time spent in NOE did not correlate with any of the other objective or subjective NOE indicators (Figure $\underline{2} 1$ ). 


\begin{tabular}{|c|c|c|c|c|c|c|c|c|c|}
\hline & 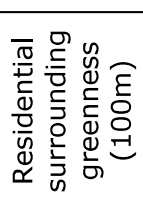 & 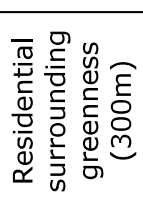 & 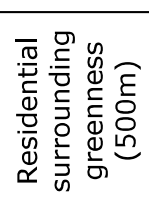 & 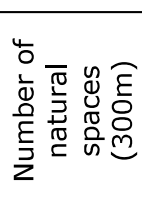 & 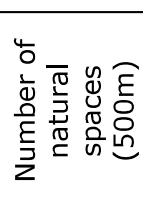 & 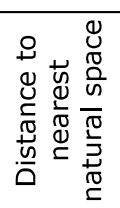 & 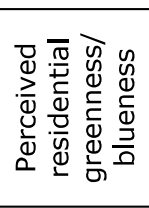 & 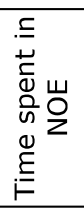 & 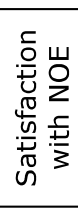 \\
\hline $\begin{array}{l}\text { Residential } \\
\text { surrounding } \\
\text { greenness } \\
(100 \mathrm{~m})\end{array}$ & 1.00 & & & & & & & & \\
\hline $\begin{array}{l}\text { Residential } \\
\text { surrounding } \\
\text { greenness } \\
(300 \mathrm{~m})\end{array}$ & 0.94 & 1.00 & & & & & & & \\
\hline $\begin{array}{l}\text { Residential } \\
\text { surrounding } \\
\text { greenness } \\
(500 \mathrm{~m})\end{array}$ & 0.91 & 0.98 & 1.00 & & & & & & \\
\hline $\begin{array}{l}\text { Number of } \\
\text { natural } \\
\text { spaces } \\
(300 \mathrm{~m})\end{array}$ & 0.34 & 0.38 & 0.38 & 1.00 & & & & & \\
\hline $\begin{array}{l}\text { Number of } \\
\text { natural } \\
\text { spaces } \\
(500 \mathrm{~m})\end{array}$ & 0.30 & 0.36 & 0.38 & 0.81 & 1.00 & & & & \\
\hline $\begin{array}{l}\text { Distance to } \\
\text { nearest } \\
\text { natural space }\end{array}$ & -0.55 & -0.57 & -0.58 & -0.43 & -0.47 & 1.00 & & & \\
\hline $\begin{array}{l}\text { Perceived } \\
\text { residential } \\
\text { greenness/blu } \\
\text { eness }\end{array}$ & 0.48 & 0.47 & 0.46 & 0.29 & 0.29 & -0.40 & 1.00 & & \\
\hline $\begin{array}{l}\text { Time spent in } \\
\text { NOE }\end{array}$ & 0.11 & 0.13 & 0.12 & 0.05 & 0.02 & -0.06 & 0.16 & 1.00 & \\
\hline $\begin{array}{l}\text { Satisfaction } \\
\text { with NOE }\end{array}$ & 0.22 & 0.24 & 0.23 & -0.01 & -0.03 & -0.25 & 0.46 & 0.07 & 1.00 \\
\hline
\end{tabular}

Figure 12. Correlation between subjective and objective NOE indicators.

Blue =positively correlated; Red=negatively correlated. Darker colour indicates stronger correlation.

\subsection{Association between NOE indicators and common somatic symptoms}

Objective neighbourhood NOE availability

Crude negative binomial models showed statistically significant positive associations between residential surrounding greenness $(100 \mathrm{~m}, 300 \mathrm{~m}$ and $500 \mathrm{~m}$ buffers) and common somatic symptoms (Table 3). However, associations disappeared after adjusting for potential confounders, with further analysis suggesting 'city' was a major confounder (Supplementary Material, Table S2). A small, statistically significant positive association was found between 
number of natural spaces ( $300 \mathrm{~m}$ buffer) and common somatic symptoms, with a higher number of natural spaces associated with a $3 \%$ higher prevalence of common somatic symptoms $(\exp (\beta) 1.03 ; 95 \%$ CI 1.00, 1.05) (Table 3$)$. No statistically significant associations were found in crude or adjusted models between the other objective NOE indicators (number of natural spaces at $500 \mathrm{~m}$; distance to nearest natural space) and common somatic symptoms (Table 3).

Investigation of interaction terms and subsequent sub-group analysis revealed statistically significant associations specific to male respondents, those living in low SES neighbourhoods, and those in Barcelona and Stoke-on-Trent. Sub-group analysis by gender showed that residential surrounding greenness $(100 \mathrm{~m}, 300 \mathrm{~m}$ and $500 \mathrm{~m})$ and number of natural space (300m and $500 \mathrm{~m}$ ) were statistically significantly associated with more common somatic symptoms among male respondents but not female respondents, and distance from nearest natural space was statistically significantly associated with fewer common somatic symptoms among male respondents only (Table 4).

\section{Subjective NOE availability, visits, and satisfaction}

In contrast, crude and adjusted models showed a small, but statistically significant negative association between satisfaction with NOE and common somatic symptoms, with a one-point higher satisfaction score associated with a $3 \%$ lower prevalence of somatic symptoms $(\exp (\beta)$ $0.97 ; 95 \%$ CI $0.96,0.98)$. No statistically significant associations were found in crude or adjusted models between the other subjective NOE indicators (perceived residential greenness/blueness; time spent in NOE) and common somatic symptoms (Table 3).

Sub-group analysis by neighbourhood SES found that a high amount of time spent in NOE among those in low SES neighbourhoods was associated with $2 \%$ lower prevalence of common somatic symptoms $(\exp (\beta) 0.98 ; 95 \%$ CI $0.96,1.00)$. No statistically significant association within medium or high SES neighbourhoods was observed (Table 5). Sub-group analysis by city found that a one-point higher perceived residential greenness/blueness was associated with $4 \%$ lower prevalence of common somatic symptoms among respondents in Stoke-onTrent $(\exp (\beta) 0.96 ; 95 \%$ CI $0.94,0.98)$ but no statistically significant associations among respondents in Barcelona, Doetinchem or Kaunas. A one-point higher NOE satisfaction score was associated with lower prevalence of common somatic symptoms in Barcelona $(\exp (\beta)$ 
$0.98 ; 95 \%$ CI $0.96,0.99)$ and Stoke-on-Trent $(\exp (\beta) 0.94 ; 95 \%$ CI $0.93,0.96)$ but no statistically significant associations in Doetinchem or Kaunas (Table 6).

Table 3. Crude and adjusted association between NOE indicators and common somatic symptoms

\begin{tabular}{|c|c|c|}
\hline $\begin{array}{l}\text { NOE indicator } \\
(n=3,481)\end{array}$ & $\begin{array}{c}\text { Crude model a } \\
\exp (\beta)(95 \% \mathrm{CI})\end{array}$ & $\begin{array}{l}\text { Adjusted model b } \\
\exp (\beta)(95 \% \mathrm{CI})\end{array}$ \\
\hline $\begin{array}{l}\text { Residential surrounding greenness - } \\
100 \mathrm{~m} \text { buffer (high vs low) }\end{array}$ & $1.08 * * *(1.04-1.12)$ & $1.03(0.98-1.07)$ \\
\hline $\begin{array}{l}\text { Residential surrounding greenness - } \\
300 \mathrm{~m} \text { buffer (high vs low) }\end{array}$ & $1.08 * * *(1.04-1.13)$ & $1.01(0.964-1.06)$ \\
\hline $\begin{array}{l}\text { Residential surrounding greenness - } \\
500 \mathrm{~m} \text { buffer (high vs low) }\end{array}$ & $1.10 * * *(1.06-1.15)$ & $1.01(0.971-1.06)$ \\
\hline $\begin{array}{l}\text { Number of natural spaces - 300m } \\
\text { buffer }\end{array}$ & $1.02 *(1.00-1.05)$ & $1.03 *(1.00-1.05)$ \\
\hline $\begin{array}{l}\text { Number of natural spaces - } 500 \mathrm{~m} \\
\text { buffer }\end{array}$ & $1.01(1.00-1.03)$ & $1.01(1.00-1.03)$ \\
\hline Distance to nearest natural space & $1.00(0.9995-1.00)$ & $1.00(0.9996-1.00)$ \\
\hline $\begin{array}{l}\text { Perceived residential } \\
\text { greenness/blueness }\end{array}$ & $0.99(0.98-1.00)$ & $0.99(0.98-1.00)$ \\
\hline Time spent in NOE (high vs low) & $1.00(0.99-1.01)$ & $1.00(0.99-1.01)$ \\
\hline Satisfaction with NOE & $0.97 * * *(0.96-0.98)$ & $0.97 * * *(0.96-0.98)$ \\
\hline
\end{tabular}

Table 4. Association between NOE and common somatic symptoms by gender

\begin{tabular}{|c|c|}
\hline NOE indicator & $\begin{array}{l}\text { Adjusted model } \\
\exp (\beta)(95 \% \mathrm{CI})\end{array}$ \\
\hline \multicolumn{2}{|l|}{$\begin{array}{l}\text { Residential surrounding greenness - } \\
100 \mathrm{~m} \text { (high vs low) }\end{array}$} \\
\hline Male & $1.07 * *(1.02-1.13)$ \\
\hline Female & $1.00(0.96-1.05)$ \\
\hline \multicolumn{2}{|l|}{$\begin{array}{l}\text { Residential surrounding greenness - } \\
300 \mathrm{~m} \text { (high vs low) }\end{array}$} \\
\hline Male & $1.06 *(1.00-1.12)$ \\
\hline Female & $0.98(0.93-1.03)$ \\
\hline \multicolumn{2}{|l|}{$\begin{array}{l}\text { Residential surrounding greenness - } \\
500 \mathrm{~m} \text { (high vs low) }\end{array}$} \\
\hline Male & $1.05 *(1.01-1.11)$ \\
\hline Female & $0.98(0.94-1.03)$ \\
\hline \multicolumn{2}{|l|}{ Distance to nearest natural space } \\
\hline Male & $0.9996 *(0.9993-0.9999)$ \\
\hline Female & $1.00(0.9998-1.00)$ \\
\hline \multicolumn{2}{|l|}{ Number of natural spaces - $300 \mathrm{~m}$ buffer } \\
\hline Male & $1.06 * *(1.02-1.09)$ \\
\hline
\end{tabular}




\begin{tabular}{|c|c|}
\hline Female & $1.00(0.98-1.03)$ \\
\hline \multicolumn{2}{|l|}{ Number of natural spaces $-500 \mathrm{~m}$ buffer } \\
\hline Male & $1.03 * *(1.01-1.05)$ \\
\hline Female & $1.00(0.98-1.02)$ \\
\hline
\end{tabular}

Note: Mixed effects negative binomial models with random intercept for neighbourhood adjusted for age, educational level, income, employment status, neighbourhood socioeconomic status, city, household composition, smoking status and dog ownership. $* \mathrm{p} \leq 0.05 ; * * \mathrm{p}<0.01$. NOE, natural outdoor environment.

Table 5. Association between time spent in NOE and common somatic symptoms by socioeconomic status

\begin{tabular}{|c|c|}
\hline NOE indicator & $\begin{array}{l}\text { Adjusted model } \\
\exp (\beta)(95 \% \mathrm{CI})\end{array}$ \\
\hline \multicolumn{2}{|l|}{ Time spent in NOE (high vs low) } \\
\hline LOW SES & $0.98 *(0.96-1.00)$ \\
\hline Medium SES & $1.01(0.99-1.02)$ \\
\hline High SES & $1.01(0.99-1.03)$ \\
\hline
\end{tabular}

Note: Mixed effects negative binomial models with random intercept for neighbourhood adjusted for age, gender, educational level, income, employment status, city, household composition, smoking status and dog ownership. ${ }^{*} \mathrm{p} \leq 0.05$. NOE, natural outdoor environment.

Table 6. Association between perceived residential greenness/blueness, satisfaction with NOE, and common somatic symptoms by city

\begin{tabular}{|c|c|}
\hline NOE indicator & $\begin{array}{l}\text { Adjusted model } \\
\exp (\beta)(95 \% \mathrm{CI})\end{array}$ \\
\hline \multicolumn{2}{|l|}{$\begin{array}{l}\text { Perceived residential } \\
\text { greenness/blueness }\end{array}$} \\
\hline Barcelona & $1.01(0.99-1.04)$ \\
\hline Doetinchem & $1.00(0.97-1.02)$ \\
\hline Kaunas & $1.00(0.97-1.02)$ \\
\hline Stoke-on-Trent & $0.96 * * *(0.94-0.98)$ \\
\hline \multicolumn{2}{|l|}{ Satisfaction with NOE } \\
\hline Barcelona & $0.98 * *(0.96-0.99)$ \\
\hline Doetinchem & $1.00(0.98-1.02)$ \\
\hline Kaunas & $0.98(0.96-1.00)$ \\
\hline Stoke-on-Trent & $0.94 * * *(0.93-0.96)$ \\
\hline
\end{tabular}

Note: Mixed effects negative binomial models with random intercept for neighbourhood adjusted for age, gender, educational level, income, employment status, neighbourhood socioeconomic status, household composition, smoking status and dog ownership. ${ }^{* *} p<0.01 ; * * * p<0.001$. NOE, natural outdoor environment. 


\subsection{Association between NOE indicators and potential mediators}

Objective neighbourhood NOE availability

Residential surrounding greenness was positively associated with social cohesion (all buffer sizes) and negatively associated with air quality concern (300m and $500 \mathrm{~m}$ buffer distances). No statistically significant association was found for number of natural spaces or distance to the nearest natural space and the potential mediators (Table 7).

Subjective NOE availability, visits, and satisfaction

Perceived residential greenness/blueness was positively associated with mental health (coef. $0.20 ; 95 \%$ CI $0.02,0.38$ ), social cohesion (coef. $0.20 ; 95 \%$ CI $0.16,0.24$ ) and outdoor physical activity $(\exp (\beta) 1.02 ; 95 \%$ CI $1.01,1.03)$, and negatively associated with air quality concern (OR $0.93 ; 95 \%$ CI $0.90,0.95$ ). Time spent in NOE was positively associated with mental health (coef. $0.41 ; 95 \%$ CI $0.21,0.60$ ), social cohesion (coef. $0.07 ; 95 \%$ CI 0.03 , 0.11 ) and outdoor physical activity $(\exp (\beta) 1.06 ; 95 \%$ CI $1.04,1.07)$. Satisfaction with NOE was positively associated with mental health (coef. $0.50 ; 95 \%$ CI $0.33,0.67$ ) and social cohesion (coef. $0.22 ; 95 \% \mathrm{CI} 0.18,0.26$ ), and negatively associated with air quality concern (OR 0.90; 95\% CI 0.88, 0.93; Table 7). 
Table 7. Association between NOE indicators and potential mediators

\begin{tabular}{|c|c|c|c|c|}
\hline NOE indicator & $\begin{array}{c}\text { Perceived } \\
\text { mental health a } \\
\text { B }(95 \% \text { CI }) \\
(n=3,479)\end{array}$ & $\begin{array}{c}\text { Social } \\
\text { cohesion b } \\
\text { B }(\mathbf{9 5 \%} \text { CI }) \\
(n=3,311)\end{array}$ & $\begin{array}{c}\text { Outdoor physical } \\
\text { activity c } \\
\exp (\beta)(95 \% \mathrm{CI}) \\
(n=3,481)\end{array}$ & $\begin{array}{r}\text { Air quality } \\
\text { concerns d } \\
\text { OR }(95 \% \text { CI }) \\
(n=3,480)\end{array}$ \\
\hline $\begin{array}{l}\text { Residential } \\
\text { surrounding } \\
\text { greenness - 100m } \\
\text { buffer (high vs low) }\end{array}$ & $\begin{array}{c}0.22 \\
(-0.50-0.94)\end{array}$ & $\begin{array}{c}0.39 * * * \\
(0.23-0.55)\end{array}$ & $\begin{array}{c}0.99 \\
(0.94-1.05)\end{array}$ & $\begin{array}{c}0.91 \\
(0.81-1.03)\end{array}$ \\
\hline $\begin{array}{l}\text { Residential } \\
\text { surrounding } \\
\text { greenness - } 300 \mathrm{~m} \\
\text { buffer (high vs low) }\end{array}$ & $\begin{array}{c}0.31 \\
(-0.40-1.02)\end{array}$ & $\begin{array}{c}0.41 * * * \\
(0.25-0.58)\end{array}$ & $\begin{array}{c}1.00 \\
(0.95-1.05)\end{array}$ & $\begin{array}{c}0.82 * * \\
(0.73-0.92)\end{array}$ \\
\hline $\begin{array}{l}\text { Residential } \\
\text { surrounding } \\
\text { greenness - 500m } \\
\text { buffer (high vs low) }\end{array}$ & $\begin{array}{c}0.27 \\
(-0.35-0.89)\end{array}$ & $\begin{array}{c}0.34 * * * \\
(0.19-0.49)\end{array}$ & $\begin{array}{c}1.00 \\
(0.96-1.04)\end{array}$ & $\begin{array}{c}0.81 * * * \\
(0.74-0.90)\end{array}$ \\
\hline $\begin{array}{l}\text { Number of natural } \\
\text { spaces }-300 m \text { buffer }\end{array}$ & $\begin{array}{c}-0.31 \\
(-0.70-0.09)\end{array}$ & $\begin{array}{c}0.04 \\
(-0.05-0.13) \\
\end{array}$ & $\begin{array}{c}1.00 \\
(0.97-1.03) \\
\end{array}$ & $\begin{array}{c}0.99 \\
(0.93-1.06) \\
\end{array}$ \\
\hline $\begin{array}{l}\text { Number of natural } \\
\text { spaces - } 500 \mathrm{~m} \text { buffer }\end{array}$ & $\begin{array}{c}-0.14 \\
(-0.40-0.13)\end{array}$ & $\begin{array}{c}0.002 \\
(-0.06-0.06)\end{array}$ & $\begin{array}{c}0.99 \\
(0.98-1.01)\end{array}$ & $\begin{array}{c}1.02 \\
(0.97-1.06)\end{array}$ \\
\hline $\begin{array}{l}\text { Distance to nearest } \\
\text { natural space }\end{array}$ & $\begin{array}{c}0.001 \\
(-0.003-0.005)\end{array}$ & $\begin{array}{c}-0.0002 \\
(-0.001-0.0007)\end{array}$ & $\begin{array}{c}1.00 \\
(0.9997-1.0003)\end{array}$ & $\begin{array}{c}1.00 \\
(0.9994-1.0006)\end{array}$ \\
\hline $\begin{array}{l}\text { Perceived residential } \\
\text { greenness/blueness }\end{array}$ & $\begin{array}{c}0.20 * \\
(0.02-0.38)\end{array}$ & $\begin{array}{c}0.20 * * * \\
(0.16-0.24)\end{array}$ & $\begin{array}{c}1.02 * * \\
(1.01-1.03)\end{array}$ & $\begin{array}{c}0.93 * * * \\
(0.90-0.95)\end{array}$ \\
\hline $\begin{array}{l}\text { Time spent in NOE } \\
\text { (high vs low) }\end{array}$ & $\begin{array}{c}0.41 * * * \\
(0.21-0.60)\end{array}$ & $\begin{array}{c}0.07 * * * \\
(0.03-0.11)\end{array}$ & $\begin{array}{c}1.06 * * * \\
(1.04-1.07)\end{array}$ & $\begin{array}{c}1.01 \\
(0.97-1.04)\end{array}$ \\
\hline $\begin{array}{l}\text { Satisfaction with } \\
\text { NOE }\end{array}$ & $\begin{array}{c}0.50 * * * \\
(0.33-0.67)\end{array}$ & $\begin{array}{c}0.22 * * * \\
(0.18-0.26) \\
\end{array}$ & $\begin{array}{c}1.01 \\
(0.99-1.02) \\
\end{array}$ & $\begin{array}{c}0.90 * * * \\
(0.88-0.93)\end{array}$ \\
\hline
\end{tabular}

Note: ${ }^{a}$ b Mixed effects linear regression models with random intercept for neighbourhood. ${ }^{c}$ Mixed effects negative binomial model with random intercept for neighbourhood. d Mixed effects logistic regression model with random intercept for neighbourhood. All models adjusted for age, gender, educational level, income, employment status, neighbourhood socioeconomic status, city, household composition, smoking status and dog ownership. *p $\leq 0.05$; $* * \mathrm{p}<0.01 ; * * * \mathrm{p}<0.001$. NOE, natural outdoor environment; OR, odds ratio.

\subsection{Association between potential mediators, NOE indicators, and common somatic symptoms}

The positive associations between number of natural spaces (300m buffer) and somatic symptoms remained statistically significant and with the same magnitude when outdoor physical activity or air quality concern were in the model, but were no longer statistically significant when mental health or social cohesion were in the model (though $\exp (\beta)$ only changed by 0.01 ) (Table 8 ). Since the number of natural spaces was not associated with any 
of the potential mediators, there is no indication that the positive association between number of natural spaces ( $300 \mathrm{~m}$ buffer) and somatic symptoms was mediated by mental health, social cohesion, outdoor physical activity or air quality concern. Furthermore, there was no direct association between residential surrounding greenness and somatic symptoms, but indirectonly mediation was observed through social cohesion and air quality concern.

Perceived mental health, social cohesion and air quality concern were significantly associated with common somatic symptoms, after adjusting for each of the objective and subjective NOE indicators. For instance, following adjustment for satisfaction with NOE, a one-point higher mental health score was associated with $2 \%$ lower prevalence of common somatic symptoms $(\exp (B) 0.98 ; 95 \%$ CI $0.98,0.99)$, a one-point higher social cohesion score was associated with $2 \%$ lower prevalence of common somatic symptoms $(\exp (B) 0.98 ; 95 \%$ CI $0.97,0.99)$, while high (vs. low) air quality concern was associated with $16 \%$ higher prevalence of common somatic symptoms (exp(B) $1.16 ; 95 \%$ CI 1.09, 1.25) (Table 8).

The negative association between satisfaction with NOE and common somatic symptoms remained statistically significant when adjusted for each of the potential mediators (perceived mental health, social cohesion, outdoor physical activity and air quality concern). However, the magnitude of the association decreased by approximately $1 \%$ when mental health, social cohesion or air quality concern were added (Table 8 ). These results suggest that better mental health, higher social cohesion and lower air quality concern (but not outdoor physical activity) partially mediated the negative association between satisfaction with NOE and common somatic symptoms. Finally, there was no direct association between perceived residential greenness/blueness and somatic symptoms, but we observed an indirect link through mental health, social cohesion and air quality concern. Similarly, an indirect association between time spent in NOE and somatic symptoms was observed through mental health and social cohesion. 


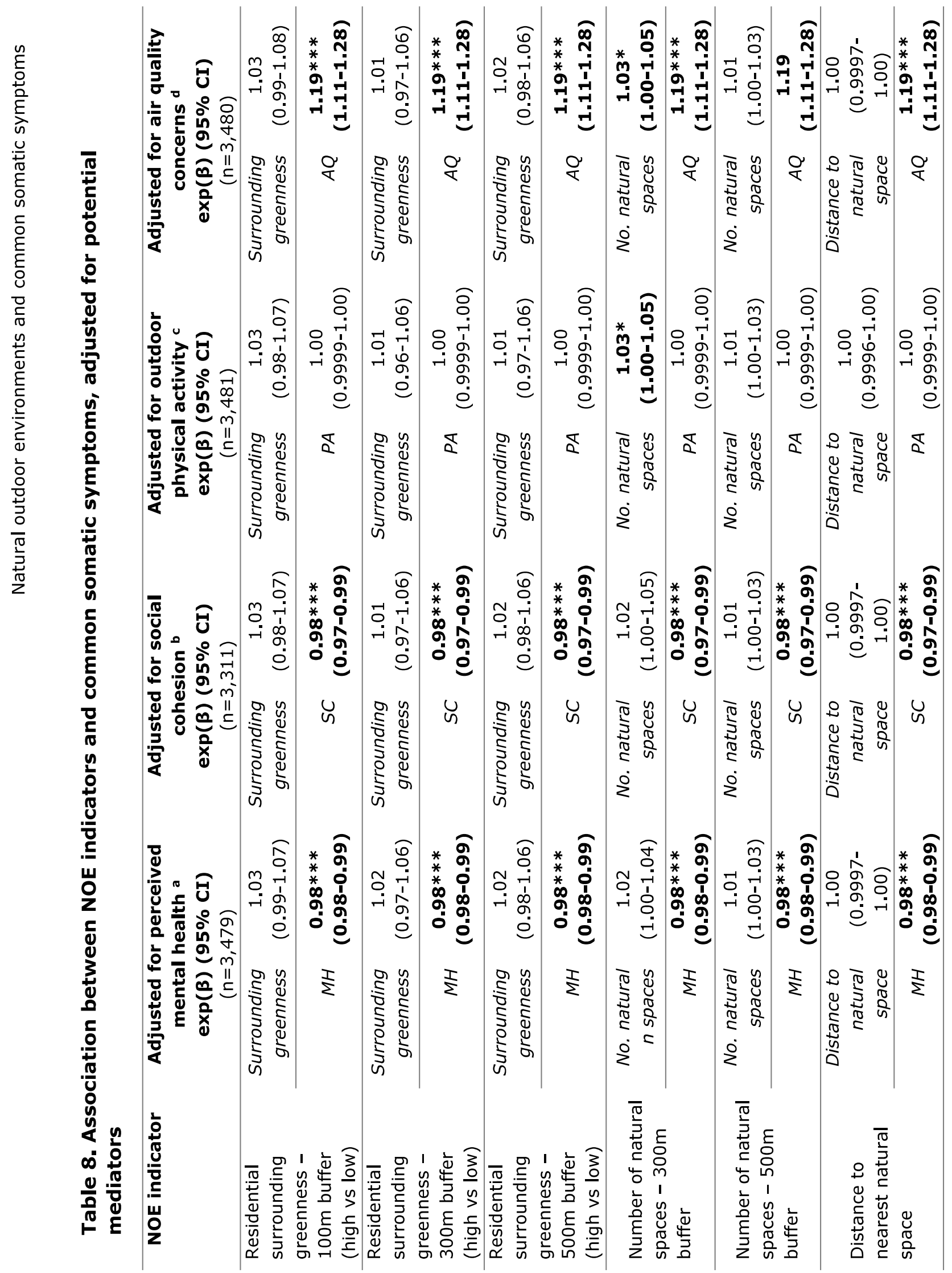




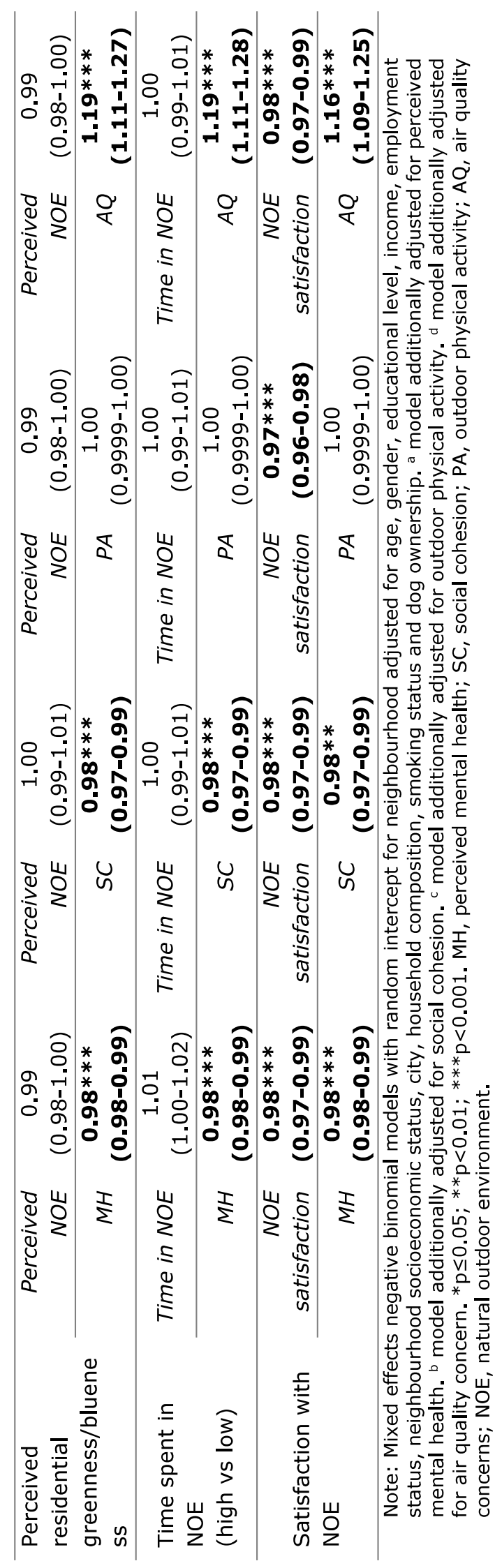




\subsection{Sensitivity analysis}

When regression analyses between NOE indicators (objective and subjective) and common somatic symptoms were repeated excluding respondents with one or more chronic disease $(n=2,223)$ or respondents with restricted mobility $(n=2,646)$, the results were comparable to analysis with the full dataset. The association between number of natural spaces $(500 \mathrm{~m}$ buffer) and common somatic symptoms excluding those with one or more chronic diseases became statistically significant in the same direction (i.e. positively associated) as the number of natural spaces (300m buffer) in the full analysis (Supplementary Material, Tables S3-S4). Additional adjustment of the main analyses for having a chronic disease and restricted mobility did not change the results (results not shown). When these analyses were repeated excluding individual somatic symptoms from the overall symptom score or using a dichotomous outcome variable (reporting any of the 9 symptoms vs no symptoms), results were also comparable to the full analysis (Supplementary Material, Table S5-S6).

When the association between number of natural spaces $(300 \mathrm{~m})$ and common somatic symptoms was analysed using a dichotomous exposure variable (typical high number of natural spaces vs typical low number of natural spaces), a statistically significant association was no longer found $(\exp (\beta) 1.04 ; 95 \%$ CI 1.00, 1.07) (Supplementary Material, Table S7). When regression analyses between NOE indicators and common somatic symptoms were repeated excluding each individual city from analysis, the negative association between NOE satisfaction and common somatic symptoms remained statistically significant in all analyses but the positive association between number of natural spaces $(300 \mathrm{~m})$ and common somatic symptoms lost statistical signficance in the analyses excluding Doetinchem and Stoke-onTrent (Supplementary Material, Table S8). 


\section{Discussion}

\subsection{Main findings}

We investigated the association between a range of objective and subjective NOE exposure indicators and number of somatic symptoms, and studied four possible pathways (physical activity, mental health, social cohesion and air quality) through mediation analysis. Subjective NOE exposure indicators demonstrated significant relationships with somatic symptoms more often than objective NOE exposure indicators. Firstly, we found that a higher level of satisfaction with neighbourhood NOE was significantly associated with lower prevalence of common somatic symptoms and that this was partially mediated by better mental health, higher social cohesion and lower air quality concern. Within low SES neighbourhoods, those that spent more time spent in NOE reported fewer somatic symptoms, and in Stoke-on-Trent, higher perceived residential greenness/blueness was associated with fewer somatic symptoms. Mediation analysis also suggested indirect associations between perceived residential greenness/blueness and common somatic symptoms (mediated by mental health, social cohesion and air quality concern), time spent in NOE and somatic symptoms (mediated by mental health and social cohesion), and residential surrounding greenness and somatic symptoms (mediated by social cohesion and air quality concern). Overall, no associations between objective NOE indicators and number of common somatic symptoms were observed. However, unexpectedly, more natural spaces within a 300m network buffer was associated with higher prevalence of somatic symptoms, and higher levels of residential surrounding greenness was associated with higher prevalence of somatic symptoms among men.

\subsection{Comparison with existing literature}

The finding that there was no statistically significant association between most indicators of NOE exposure and common somatic symptoms aligns with previous research by Zock et al., (2018), which reports no statistically significant associations (Zock et al., 2018). However, two previous Dutch studies using electronic health records from general practitioner (GP) visits have reported statistically significant negative associations between percentage of green space and common somatic symptoms (Groenewegen et al., 2018; Maas et al., 2009). The differences in findings may be due to these studies using much larger sample sizes (up to 1.16 million for one study using electronic health records (Groenewegen et al., 2018)) than 
the current study, providing them with higher statistical power. The studies used somatic symptom data collected via GP records, meaning that those included in the studies were sufficiently concerned about their symptoms to have visited a medical professional. This suggests that the persistence and/or level of severity of the symptoms may be an important factor in the association between common somatic symptoms and green space. The variability in findings across different studies is perhaps not surprising given the variation in outcome and exposure measurements and the complex interplay of biological, psychological and social factors thought to be involved in the reporting of common somatic symptoms (Huss et al., 2004). In particular, it has been suggested that personality traits may play an important role in symptom reporting (Huss et al., 2004; Watson and Pennebaker, 1989). This aspect was not explored in the current or previous studies.

The observed association between number of natural spaces at $300 \mathrm{~m}$ and higher amount of common somatic symptoms contradicts the study hypothesis and has not been reported in previous studies using similar measurements of natural space_(Triguero-Mas et al., 2017). The reasons behind this association are unclear. There is some previous research linking exposure to green space with increased allergies (World Health Organization (WHO), 2016) but since very few of the symptoms captured in the current study are typically associated with allergy, this explanation is unlikely. In addition, gGiven the cross-sectional nature of the study, the possibility of reverse causation cannot be ruled out, whereby those who experience more symptoms choose to live in areas with higher numbers of natural spaces. If these explanations were true, one might expect to see more consistency with the results for other NOE indicators, although, as highlighted in Figure $1 \underline{2}$, the correlation between different NOE indicators is not particularly strong. Alternatively, it is possible that this statistically significant association is a chance finding or influenced by the highly skewed nature of the variable; there was a median of one natural space within each $300 \mathrm{~m}$ residential buffer but a maximum of 15 . Doetinchem, the city with the most natural spaces within $300 \mathrm{~m}$, but where participants were on average older and reported more common somatic symptoms compared to the other cities, might be driving this association, as shown by sensitivity analysis. It should also be noted that the other sensitivity analyses further produced inconsistent findings for the association between this exposure variable and common somatic symptoms, suggesting that the variable is sensitive to the method of analysis. 
The finding that time spent in NOE was significantly negatively associated with common somatic symptoms in low SES neighbourhoods aligns with findings from several previous studies, including those by Groenewegen et al., (2018), and Maas et al., (2009). Both found stronger negative associations between green space and somatic symptoms among low SES groups (Groenewegen et al., 2018; Maas et al., 2009). It has been hypothesised that individuals in low SES neighbourhoods may benefit more from the availability of green space because they tend to spend a larger proportion of their time close to home and have less means to access NOE away from home, or because low SES groups tend to experience poorer overall health than high SES groups, and could have more opportunity for benefit (Dadvand et al., 2012; de Vries et al., 2003). In relation to time spent in NOE, there are some_notable differences between the findings of the current study and the study undertaken by TrigueroMas et al., (2017), on a subset of the PHENOTYPE dataset (Triguero-Mas et al., 2017). Partly Econsistent with the current study, the researchers found no statistically significant association between common somatic symptoms and availability of NOE, but they did find-a statistically significant negative association between time spent in surrounding greenness and somatic symptoms, an observation we only made in the low SES group. They also found stronger relationships between less somatisation and contact with surrounding greenness among men, which was not observed in our study. We did observe that the objective residential NOE exposure indicators were associated with more common somatic symptoms among male respondents but not female respondents. - The inconsistency between the two studies may be explained by differences in the data used. While the study by Triguero-Mas et al. involved a subset of participants from the PHENOTYPE study, data were collected via a smartphone over a 7-day period. This means that data on green space use was collected objectively using GPS tracking and somatic symptom data were collected twice a day over the course of a week rather than at a single time-point, making the data collection methods less prone to recall bias than the methods used in the current study (Triguero-Mas et al., 2017).

To our knowledge, the association between satisfaction with neighbourhood NOE and common somatic symptoms has not previously been reported. Other studies have, however, looked at individual components of the satisfaction score (e.g. quality, safety) (de Vries et al., 2013; Groenewegen et al., 2018). For example, de Vries et al. (2013) found that those living in greener areas reported fewer acute health complaints (which includes somatic symptoms) but that quality of green space may be a more important factor than quantity (de Vries et al., 
2013). Our findings support the possibility that features of NOE beyond quantity are important in shaping the relationship between NOE and health. From the current study, it is not possible to know whether those who have more positive perceptions of NOE report fewer symptoms because they benefit from this experience or whether their response to both questions is influenced by other factors (e.g. personality traits). This area therefore merits further attention.

The mediation analysis suggests that perceived better mental health, higher social cohesion and lower air quality concerns may play mediating roles in the relationship between satisfaction with NOE and common somatic symptoms. These findings align with the study of de Vries et al., (2013), which found that stress and social cohesion, but not physical activity, played mediating roles in the relationship between green space and acute health complaints (de Vries et al., 2013). Triguero-Mas et al., (2017) also found that a significant negative association between time spent in NOE and somatic symptoms was mediated by stressreduction (Triguero-Mas et al., 2017). The findings partially support our study hypothesis, which predicted mediating roles for these three factors and (incorrectly) for outdoor physical activity (Hartig et al., 2014).

\subsection{Strengths and limitations}

The current study is one of the first to examine the association between NOE exposure and common somatic symptoms outside a healthcare setting, providing insight into this association for a broad study population. A key strength of the study is the large and diverse study population, which covers multiple European cities. Study sites were specifically selected to capture individuals from neighbourhoods with varied SES and levels of NOE, improving the generalisability of the study findings. The study also assessed a wide range of NOE indicators, encompassing both objective measures and the perceptions of the study participants. Each NOE indicator captures a slightly different aspect of neighbourhood greenness and therefore provides insight into the most relevant aspects for health.

The study also has several limitations that are important to consider when interpreting results. Firstly, missing data points resulted in the exclusion of $12 \%$ of the total observations from the dataset, which may have negatively impacted the representativeness of the sample. Secondly, the cross-sectional design of the study means that it is not possible to draw conclusions about causal relationships. For example, it cannot be ruled out that those that experience more somatic symptoms choose to live in areas with higher numbers of green 
spaces. Thirdly, it is possible that our findings for the subjective NOE indicators were affected by same-source bias as both the exposure variables and the outcome came from self-reported data. As a result, an individual's personality or mental state may have led them to provide similar ratings for both exposure and outcome, regardless of the objective situation. This is particularly pertinent given the role that personality is thought to play in the reporting of common somatic symptoms (Watson and Pennebaker, 1989). Finally, while the indicators (perceived mental health, outdoor physical activity, social cohesion, air quality concern) used in the mediation analysis to examine the four pathways between NOE exposure and common somatic symptoms were the best available to us, other indicators may have been more appropriate had the data been available. For example, it would have been preferable to examine perceived stress rather than perceived mental health, and to examine an objective measure of air quality rather than air quality concern.

There are a number of limitations relating to the measurement of common somatic symptoms that must also be considered. It cannot be ruled out that some of the symptoms captured in the somatic symptom questionnaire could be attributed to underlying illness. However, this risk was minimised by using questions based on a validated questionnaire and by conducting sensitivity analyses adjusting for and excluding those with restricted mobility or suffering from a chronic disease. Finally, data on common somatic symptoms were transformed into count data for the analysis due to the non-normal distribution of the original variable. While this assisted analysis, it also led to information loss because the transformed data did not capture information on duration of symptoms. This meant that someone who experienced a headache once during the week was treated the same as someone who experienced one every day.

\subsection{Implications for policymakers}

While this study found little evidence of a statistically significant association between objective NOE exposure and common somatic symptoms, the significant association between satisfaction with NOE and common somatic symptoms suggests that individual perceptions of NOE and features of NOE beyond quantity are important to consider when designing urban areas that promote health. Furthermore, the differences in findings between socioeconomic groups provides further support for the potential benefits of introducing NOE in low SES neighbourhoods. While the associations found in the study are small, interventions with this level of health benefit can make an important contribution to health at a population level.

\subsection{Future research directions}


Longitudinal studies are needed in order to investigate a possible causal relationship between satisfaction with NOE and common somatic symptoms and to better understand the potential underlying mechanisms through which any benefits occur. These studies should investigate the four potential mediators explored in the current study, using the most appropriate measures for each mediator (e.g. perceived stress rather than perceived mental health). Given the role that personality traits are thought to have in the reporting of common somatic symptoms-and the difference in the study findings between individual and neighbourhood level NOE satisfaction, future studies should also consider how personality influences the relationship between NOE exposure and common somatic symptoms.

\section{Conclusions}

This study found that higher satisfaction with NOE was associated with a lower prevalence of common somatic symptoms, which may be partly due to better mental health, higher social cohesion and lower concern about air quality. The study also found evidence of an association between time spent in NOE and common somatic symptoms in low SES neighbourhoods. There was little evidence of an association between objectively-determined NOE exposure and common somatic symptoms. Further research is needed to confirm these findings and better understand the link between NOE satisfaction and other perceived NOE indicators and common somatic symptoms.

\section{References}

Baron, R.M., Kenny, D.A., 1986. The moderator-mediator variable distinction in social psychological research: conceptual, strategic, and statistical considerations. J. Pers. Soc. Psychol. 51, 1173-82.

Barsky, A.J., Orav, E.J., Bates, D.W., 2005. Somatization increases medical utilization and costs independent of psychiatric and medical comorbidity. Arch. Gen. Psychiatry 62, 903-910. https://doi.org/10.1001/archpsyc.62.8.903

Dadvand, P., de Nazelle, A., Figueras, F., Basagaña, X., Su, J., Amoly, E., Jerrett, M., Vrijheid, M., Sunyer, J., Nieuwenhuijsen, M.J., 2012. Green space, health inequality and pregnancy. Environ. Int. 40, 110-5. https://doi.org/10.1016/j.envint.2011.07.004 
de Vries, S., van Dillen, S.M.E., Groenewegen, P.P., Spreeuwenberg, P., 2013. Streetscape greenery and health: stress, social cohesion and physical activity as mediators. Soc. Sci. Med. 94, 26-33. https://doi.org/10.1016/j.socscimed.2013.06.030

de Vries, S., Verheij, R.A., Groenewegen, P.P., Spreeuwenberg, P., 2003. Natural Environments-Healthy Environments? An Exploratory Analysis of the Relationship between Greenspace and Health. Environ. Plan. A 35, 1717-1731. https://doi.org/10.1068/a35111

de Waal, M.W.M., Arnold, I.A., Eekhof, J.A.H., van Hemert, A.M., 2004. Somatoform disorders in general practice: Prevalence, functional impairment and comorbidity with anxiety and depressive disorders. Br. J. Psychiatry 184, 470-476. https://doi.org/10.1192/bjp.184.6.470

Ewert, A., Chang, Y., 2018. Levels of Nature and Stress Response. Behav Sci 8. https://doi.org/10.3390/bs8050049

Frumkin, H., Bratman, G.N., Breslow, S.J., Cochran, B., Kahn Jr, P.H., Lawler, J.J., Levin, P.S., Tandon, P.S., Varanasi, U., Wolf, K.L., Wood, S.A., 2017. Nature Contact and Human Health: A Research Agenda. Environ. Health Perspect. 125, 075001. https://doi.org/10.1289/EHP1663

Gong, Y., Palmer, S., Gallacher, J., Marsden, T., Fone, D., 2016. A systematic review of the relationship between objective measurements of the urban environment and psychological distress. Environ. Int. 96, 48-57. https://doi.org/10.1016/j.envint.2016.08.019

Groenewegen, P.P., Zock, J.-P., Spreeuwenberg, P., Helbich, M., Hoek, G., Ruijsbroek, A., Strak, M., Verheij, R., Volker, B., Waverijn, G., Dijst, M., 2018. Neighbourhood social and physical environment and general practitioner assessed morbidity. Health Place 49, 68-84. https://doi.org/10.1016/J.HEALTHPLACE.2017.11.006

Gureje, O., Simon, G.E., Ustun, T.B., Goldberg, D.P., 1997. Somatization in cross-cultural perspective: a World Health Organization study in primary care. Am. J. Psychiatry 154, 989-995.

Hartig, T., Mitchell, R., de Vries, S., Frumkin, H., 2014. Nature and health. Annu. Rev. Public Health 35, 207-28. https://doi.org/10.1146/annurev-publhealth-032013-182443

Huss, A., Küchenhoff, J., Bircher, A., Heller, P., Kuster, H., Niederer, M., Scartazzini, G., Schwarzenbach, S., Waeber, R., Wegmann, L., Braun-Fahrländer, C., 2004. Symptoms attributed to the environment - a systematic, interdisciplinary assessment. Int. J. Hyg. Environ. Health 207, 245-254. https://doi.org/http://dx.doi.org/10.1078/1438-463900286

Kaplan, S., 1995. The restorative benefits of nature: Toward an integrative framework. J. Environ. Psychol. 15, 169-182. https://doi.org/10.1016/0272-4944(95)90001-2

Korpela, K.M., Ylen, M., 2007. Perceived health is associated with visiting natural favourite places in the vicinity. Heal. Place 13, 138-151. https://doi.org/10.1016/j.healthplace.2005.11.002

Kruize, H., van Kamp, I., van den Berg, M., van Kempen, E., Wendel-Vos, W., Ruijsbroek, A., Swart, W., Maas, J., Gidlow, C., Smith, G., Ellis, N., Hurst, G., Masterson, D., Triguero-Mas, M., Cirach, M., Grazuleviciene, R., van den Hazel, P., Nieuwenhuijsen, 
M., 2019. Exploring mechanisms underlying the relationship between the natural outdoor environment and health and well-being - Results from the PHENOTYPE project. Environ. Int. https://doi.org/10.1016/j.envint.2019.105173

Lachowycz, K., Jones, A.P., 2011. Greenspace and obesity: a systematic review of the evidence. Obes. Rev. 12, e183-9. https://doi.org/10.1111/j.1467-789X.2010.00827.x

Lipowski, Z.J., 1988. Somatization: the concept and its clinical application. Am. J. Psychiatry $145,1358-1368$.

Maas, Jolanda, van Dillen, S.M.E., Verheij, R.A., Groenewegen, P.P., 2009. Social contacts as a possible mechanism behind the relation between green space and health. Heal. Place 15, 586-595. https://doi.org/10.1016/j.healthplace.2008.09.006

Maas, J, Verheij, R.A., de Vries, S., Spreeuwenberg, P., Schellevis, F.G., Groenewegen, P.P., 2009. Morbidity is related to a green living environment. J. Epidemiol. Community Health 63, 967-973. https://doi.org/10.1136/jech.2008.079038

Markevych, I., Schoierer, J., Hartig, T., Chudnovsky, A., Hystad, P., Dzhambov, A.M., de Vries, S., Triguero-Mas, M., Brauer, M., Nieuwenhuijsen, M.J., Lupp, G., Richardson, E.A., Astell-Burt, T., Dimitrova, D., Feng, X., Sadeh, M., Standl, M., Heinrich, J., Fuertes, E., 2017. Exploring pathways linking greenspace to health: Theoretical and methodological guidance. Environ. Res. 158, 301-317. https://doi.org/10.1016/j.envres.2017.06.028

Miedema, H.M., Oudshoorn, C.G., 2001. Annoyance from transportation noise: relationships with exposure metrics DNL and DENL and their confidence intervals. Environ. Health Perspect. 109, 409-16.

Nieuwenhuijsen, M.J., Khreis, H., Triguero-Mas, M., Gascon, M., Dadvand, P., 2016. Fifty Shades of Green: Pathway to Healthy Urban Living. Epidemiology. https://doi.org/10.1097/EDE.0000000000000549

Nieuwenhuijsen, M.J., Kruize, H., Gidlow, C., Andrusaityte, S., Antó, J.M., Basagaña, X., Cirach, M., Dadvand, P., Danileviciute, A., Donaire-Gonzalez, D., Garcia, J., Jerrett, M., Jones, M., Julvez, J., van Kempen, E., van Kamp, I., Maas, J., Seto, E., Smith, G., Triguero, M., Wendel-Vos, W., Wright, J., Zufferey, J., van den Hazel, P.J., Lawrence, R., Grazuleviciene, R., 2014. Positive health effects of the natural outdoor environment in typical populations in different regions in Europe (PHENOTYPE): a study programme protocol. BMJ Open 4, e004951. https://doi.org/10.1136/bmjopen-2014-004951

Piccininni, C., Michaelson, V., Janssen, I., Pickett, W., 2018. Outdoor play and nature connectedness as potential correlates of internalized mental health symptoms among Canadian adolescents. Prev. Med. (Baltim). 112, 168-175. https://doi.org/https://doi.org/10.1016/j.ypmed.2018.04.020

Rask, M.T., Rosendal, M., Fenger-Grøn, M., Bro, F., Ørnbøl, E., Fink, P., 2015. Sick leave and work disability in primary care patients with recent-onset multiple medically unexplained symptoms and persistent somatoform disorders: a 10-year follow-up of the FIP study. Gen. Hosp. Psychiatry 37, 53-59. https://doi.org/https://doi.org/10.1016/j.genhosppsych.2014.10.007

Roe, J., Ward Thompson, C., Aspinall, P., Brewer, M., Duff, E., Miller, D., Mitchell, R., Clow, A., 2013. Green Space and Stress: Evidence from Cortisol Measures in Deprived Urban 
Communities. Int. J. Environ. Res. Public Health 10, 4086-4103. https://doi.org/10.3390/ijerph10094086

Rosmalen, J.G.M., Neeleman, J., Gans, R.O.B., de Jonge, P., 2007. The association between neuroticism and self-reported common somatic symptoms in a population cohort. $\mathrm{J}$. Psychosom. Res. 62, 305-311. https://doi.org/10.1016/j.jpsychores.2006.10.014

Ruijsbroek, A., Mohnen, S.M., Droomers, M., Kruize, H., Gidlow, C., Gražulevičiene, R., Andrusaityte, S., Maas, J., Nieuwenhuijsen, M.J., Triguero-Mas, M., Masterson, D., Ellis, N., van Kempen, E., Hardyns, W., Stronks, K., Groenewegen, P.P., 2017.

Neighbourhood green space, social environment and mental health: an examination in four European cities. Int. J. Public Health. https://doi.org/10.1007/s00038-017-0963-8

Sampson, R.J., Raudenbush, S.W., Earls, F., 1997. Neighborhoods and Violent Crime: A Multilevel Study of Collective Efficacy. Science (80-. ). 277.

Sanz-Barbero, B., Otero García, L., Blasco Hernández, T., 2012. The effect of distance on the use of emergency hospital services in a Spanish region with high population dispersion: A multilevel analysis. Med. Care 50, 27-34. https://doi.org/10.1097/MLR.0b013e31822d5e03

Smith, G., Cirach, M., Swart, W., Dèdelè, A., Gidlow, C., van Kempen, E., Kruize, H., Gražulevičienè, R., Nieuwenhuijsen, M.J., 2017. Characterisation of the natural environment: quantitative indicators across Europe. Int. J. Health Geogr. 16, 16. https://doi.org/10.1186/s12942-017-0090-z

Terluin, B., van Marwijk, H.W., Ader, H.J., de Vet, H.C., Penninx, B.W., Hermens, M.L., van Boeijen, C.A., van Balkom, A.J., van der Klink, J.J., Stalman, W.A., 2006. The FourDimensional Symptom Questionnaire (4DSQ): a validation study of a multidimensional self-report questionnaire to assess distress, depression, anxiety and somatization. BMC Psychiatry 6, 34. https://doi.org/10.1186/1471-244X-6-34

Terluin, B., van Rhenen, W., Anema, J.R., Taris, T.W., 2011. Psychological symptoms and subsequent sickness absence. Int Arch Occup Env. Heal. 84, 825-837. https://doi.org/https://doi.org/10.1007/s00420-011-0637-4

Triguero-Mas, M., Donaire-Gonzalez, D., Seto, E., Valentín, A., Martínez, D., Smith, G., Hurst, G. , Carrasco-Turigas, G., Masterson, D., van den Berg, M., Ambròs, A., Martínez-Íñiguez, T., Dedele, A., Ellis, N., Grazulevicius, T., Voorsmit, M., Cirach, M., Cirac-Claveras, J., Swart, W., Clasquin, E., Ruijsbroek, A., Maas, J., Jerret, M., Gražulevičienè, R., Kruize, H., Gidlow, C.J., Nieuwenhuijsen, M.J., 2017. Natural outdoor environments and mental health: Stress as a possible mechanism. Environ. Res. 159, 629-638. https://doi.org/10.1016/j.envres.2017.08.048

Turnbull, J., Martin, D., Lattimer, V., Pope, C., Culliford, D., 2008. Does distance matter? Geographical variation in GP out-of-hours service use: an observational study. $\mathrm{Br}$. J. Gen. Pract. 58, 471-477. https://doi.org/10.3399/bjgp08X319431

Tyrväinen, L., Ojala, A., Korpela, K., Lanki, T., Tsunetsugu, Y., Kagawa, T., 2014. The influence of urban green environments on stress relief measures: A field experiment. $\mathrm{J}$. Environ. Psychol. 38, 1-9. https://doi.org/10.1016/j.jenvp.2013.12.005

Ulrich, R.S., Simons, R.F., Losito, B.D., Fiorito, E., Miles, M.A., Zelson, M., 1991. Stress recovery during exposure to natural and urban environments. J. Environ. Psychol. 11, 


\section{1-230. https://doi.org/10.1016/S0272-4944(05)80184-7}

United Nations - Department of Economic and Social Affairs - Population Division, 2018. World Urbanization Prospects: The 2018 Revision, Online Edition. [WWW Document]. URL https://esa.un.org/unpd/wup/ (accessed 8.21.18).

van den Berg, A.E., Maas, J., Verheij, R.A., Groenewegen, P.P., 2010. Green space as a buffer between stressful life events and health. Soc Sci Med 70, 1203-1210. https://doi.org/10.1016/j.socscimed.2010.01.002

van Poppel, M.N.M., Chinapaw, M.J.M., Mokkink, L.B., van Mechelen, W., Terwee, C.B., 2010. Physical Activity Questionnaires for Adults. Sport. Med. 40, 565-600. https://doi.org/10.2165/11531930-000000000-00000

Ware, J.E., Sherbourne, C.D., 1992. The Mos 36-Item Short-Form Health Survey (Sf-36) .1. Conceptual-Framework and Item Selection. Med. Care 30, 473-483. https://doi.org/10.1097/00005650-199206000-00002

Watson, D., Pennebaker, J.W., 1989. Health complaints, stress, and distress: Exploring the central role of negative affectivity. Psychol. Rev. 96, 234-254. https://doi.org/10.1037/0033-295X.96.2.234

Weier, J., Herring, D., 2000. Measuring Vegetation (NDVI \& EVI) [WWW Document]. URL http://earthobservatory.nasa.gov/Features/MeasuringVegetation/measuring_vegetatio n_2.php (accessed 6.28.18).

Wendel-Vos, G.C.W., Schuit, A.J., Saris, W.H.M., Kromhout, D., 2003. Reproducibility and relative validity of the short questionnaire to assess health-enhancing physical activity. J. Clin. Epidemiol. 56, 1163-9.

White, M.P., Pahl, S., Wheeler, B.W., Depledge, M.H., Fleming, L.E., 2017. Natural environments and subjective wellbeing: Different types of exposure are associated with different aspects of wellbeing. Health Place 45, 77-84. https://doi.org/10.1016/j.healthplace.2017.03.008

Won, J., Lee, C., Forjuoh, S.N., Ory, M.G., 2016. Neighborhood safety factors associated with older adults' health-related outcomes: A systematic literature review. Soc. Sci. Med. 165, 177-186. https://doi.org/https://doi.org/10.1016/j.socscimed.2016.07.024

World Medical Association, 2013. Declaration of Helsinki: Ethical principles for medical research involving human subjects. JAMA - J. Am. Med. Assoc. https://doi.org/10.1001/jama.2013.281053

Xu, T., Zhu, G., Han, S., 2017. Study of depression influencing factors with zero-inflated regression models in a large-scale population survey. BMJ Open 7, e016471. https://doi.org/10.1136/bmjopen-2017-016471

Zaninotto, P., Falaschetti, E., 2011. Comparison of methods for modelling a count outcome with excess zeros: application to Activities of Daily Living (ADL-s). J. Epidemiol. Community Heal. 65, 205-210. https://doi.org/10.1136/jech.2008.079640

Zhao, X., Lynch, J.G., Chen, Q., 2010. Reconsidering Baron and Kenny: Myths and Truths about Mediation Analysis. J. Consum. Res. 37, 197-206.

https://doi.org/10.1086/651257 
Zijlema, W.L., Avila-Palencia, I., Triguero-Mas, M., Gidlow, C., Maas, J., Kruize, H., Andrusaityte, S., Grazuleviciene, R., Nieuwenhuijsen, M.J., 2018. Active commuting through natural environments is associated with better mental health: Results from the PHENOTYPE project. Environ. Int. 121, 721-727.

https://doi.org/10.1016/J.ENVINT.2018.10.002

Zijlema, W.L., Stolk, R.P., Löwe, B., Rief, W., White, P.D., Rosmalen, J.G.M., 2013. How to assess common somatic symptoms in large-scale studies: A systematic review of questionnaires. J. Psychosom. Res. 74.

https://doi.org/10.1016/j.jpsychores.2013.03.093

Zock, J.-P., Verheij, R., Helbich, M., Volker, B., Spreeuwenberg, P., Strak, M., Janssen, N.A.H., Dijst, M., Groenewegen, P., 2018. The impact of social capital, land use, air pollution and noise on individual morbidity in Dutch neighbourhoods. Environ. Int. 121 453-460. https://doi.org/10.1016/J.ENVINT.2018.09.008 


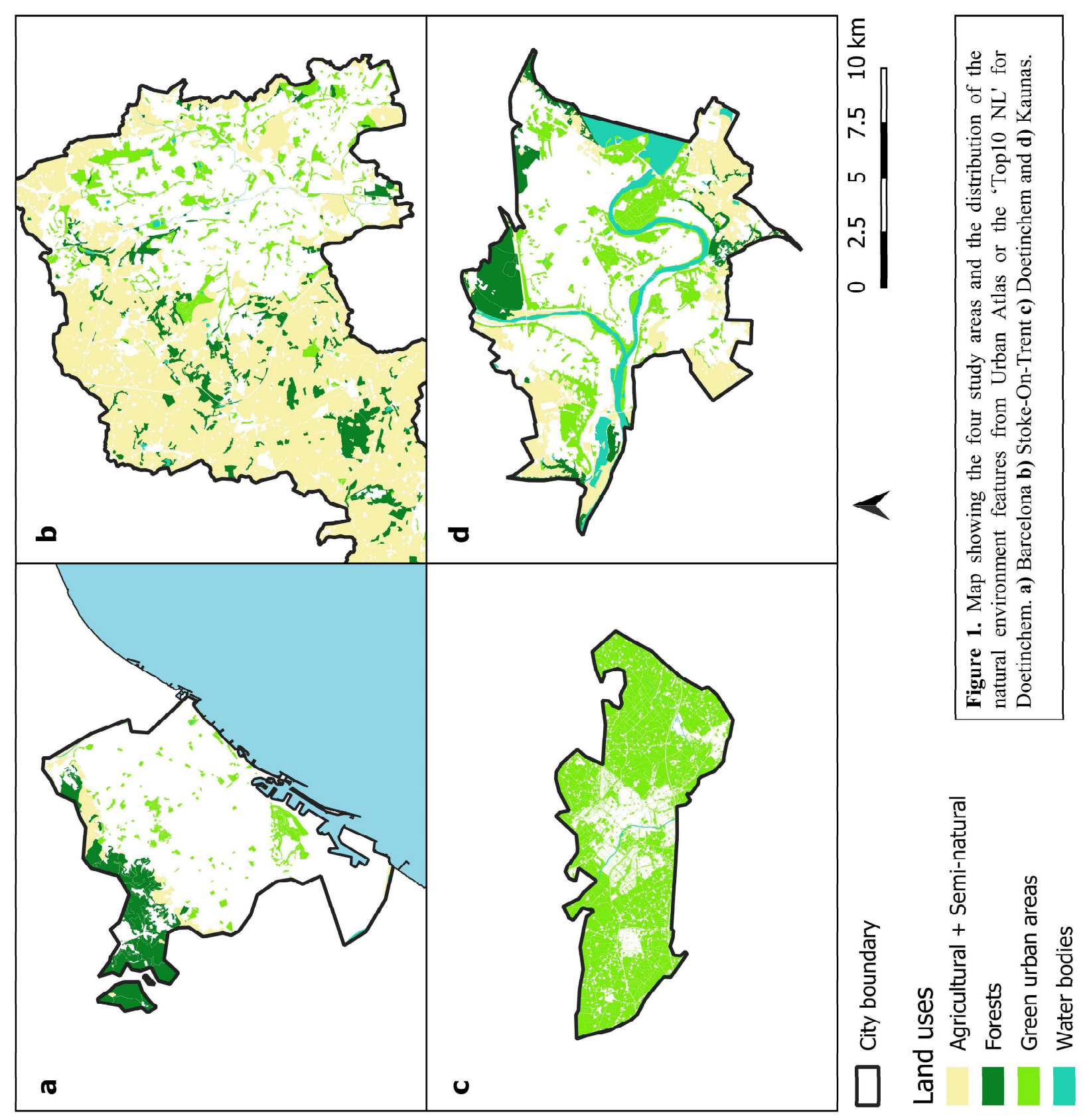



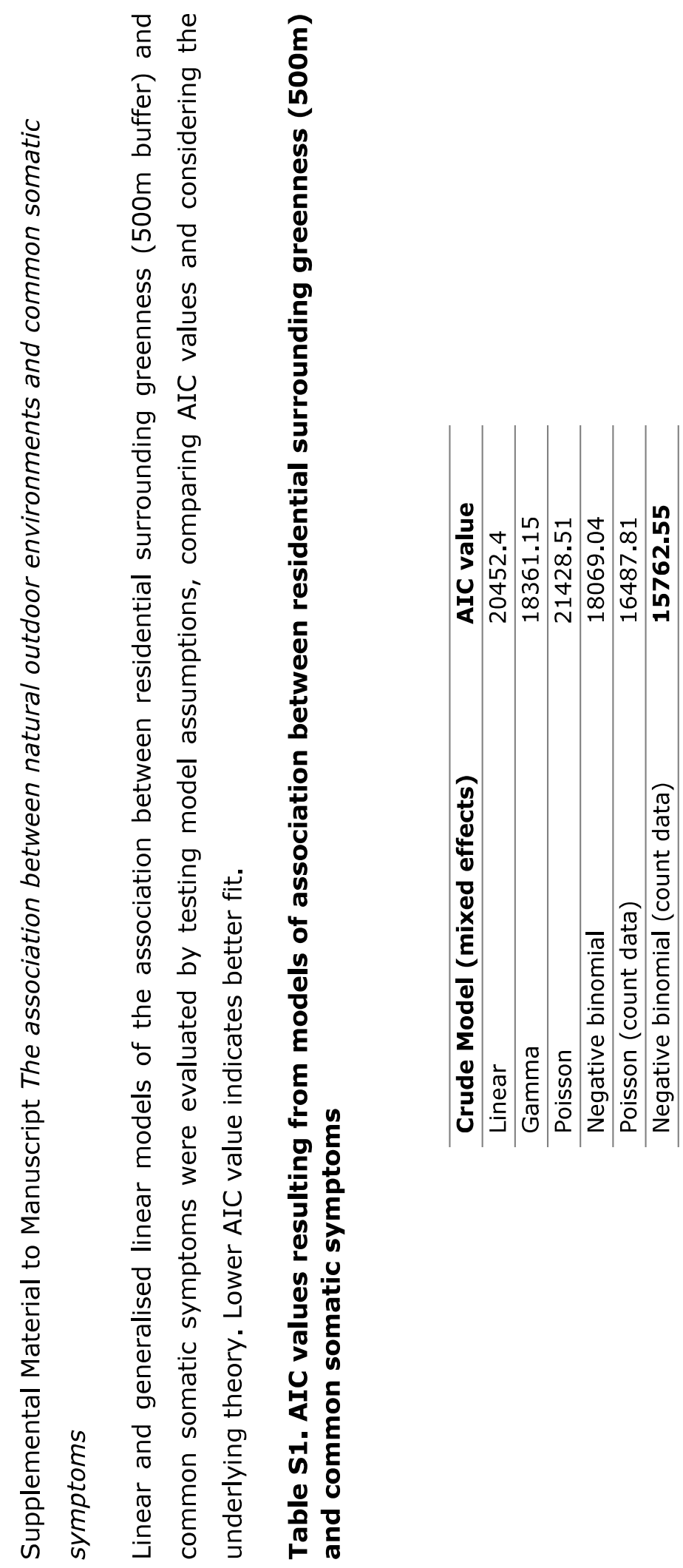

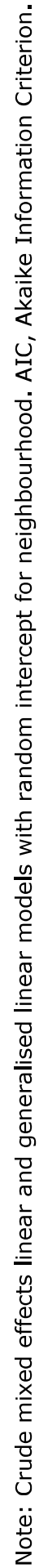









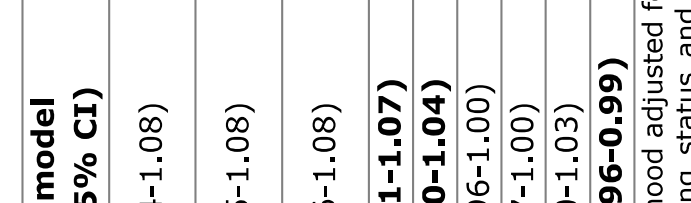




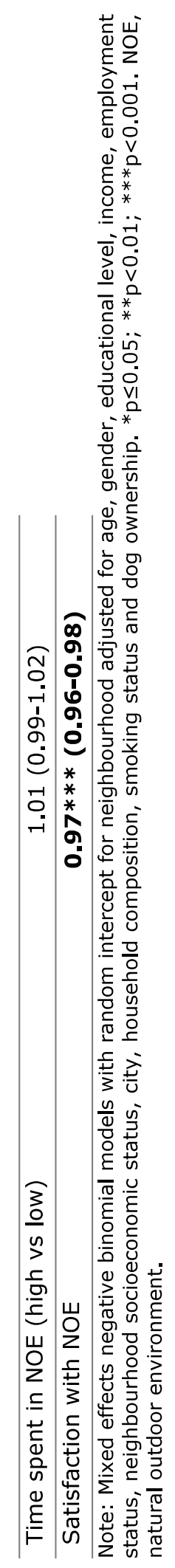




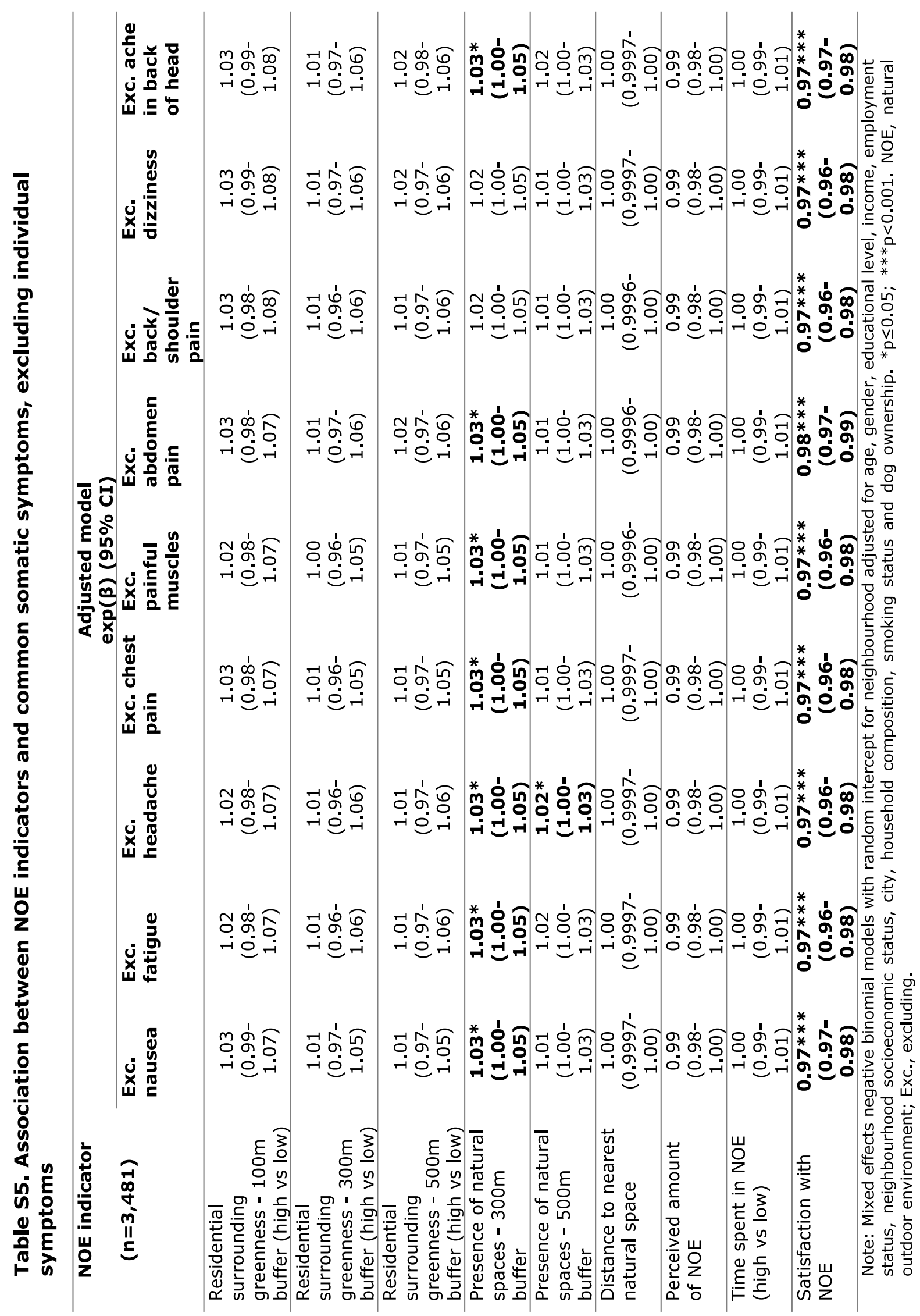


Table S6. Adjusted association between NOE indicators and common somatic symptoms (reporting any of the 9 symptoms vs no symptoms)

\begin{tabular}{|c|c|}
\hline $\begin{array}{c}\text { NOE indicator } \\
(n=\mathbf{3}, \mathbf{4 8 1})\end{array}$ & $\begin{array}{l}\text { Adjusted model } \\
\text { OR }(95 \% \mathrm{CI})\end{array}$ \\
\hline $\begin{array}{l}\text { Residential surrounding greenness - } \\
100 \mathrm{~m} \text { buffer (high vs low) }\end{array}$ & $1.12(0.97-1.30)$ \\
\hline $\begin{array}{l}\text { Residential surrounding greenness - } \\
300 \mathrm{~m} \text { buffer (high vs low) }\end{array}$ & $1.13(0.98-1.30)$ \\
\hline $\begin{array}{l}\text { Residential surrounding greenness - } \\
500 \mathrm{~m} \text { buffer (high vs low) }\end{array}$ & $1.13(1.00-1.27)$ \\
\hline $\begin{array}{l}\text { Presence of natural spaces }-300 m \\
\text { buffer }\end{array}$ & $1.12 * *(1.04-1.21)$ \\
\hline $\begin{array}{l}\text { Presence of natural spaces }-500 m \\
\text { buffer }\end{array}$ & $1.07 * *(1.02-1.12)$ \\
\hline Distance to nearest natural space & $1.00(0.999-1.00)$ \\
\hline Perceived amount of NOE & $0.96 *(0.93-0.99)$ \\
\hline Time spent in NOE (high vs low) & $1.03(0.99-1.07)$ \\
\hline Satisfaction with NOE & $0.93 * * *(0.91-0.96)$ \\
\hline
\end{tabular}

Note: Mixed effects logistic regression model with random intercept for neighbourhood. Adjusted for age, gender, educational level, income, employment status, neighbourhood socioeconomic status, city, household composition, smoking status and dog ownership. *p $\leq 0.05 ; * * p<0.01 ; * * * p<0.001$. NOE, natural outdoor environment; OR, odds ratio. 
Table S7. Association between presence of green spaces within a $300 \mathrm{~m}$ residential network buffer and common somatic symptoms - continuous and dichotomous variables

\begin{tabular}{lc}
\hline \multicolumn{1}{c}{ NOE indicator } & $\begin{array}{c}\text { Adjusted model } \\
\exp (\boldsymbol{\beta})(\mathbf{9 5 \%} \mathbf{C I})\end{array}$ \\
\hline $\begin{array}{l}\text { Presence of natural spaces }-300 \mathrm{~m} \\
\text { buffer (continuous) }\end{array}$ & $\mathbf{1 . 0 3 * ( \mathbf { 1 . 0 0 - 1 . 0 5 ) }}$ \\
\hline $\begin{array}{l}\text { Presence of natural spaces }-300 \mathrm{~m} \\
\text { buffer (high vs low) }\end{array}$ & $1.04(1.00-1.07)$
\end{tabular}

Note: Mixed effects negative binomial models with random intercept for neighbourhood adjusted for age, gender, educational level, income, employment status, neighbourhood socioeconomic status, city, household composition, smoking status and dog ownership. ${ }^{*} \mathrm{p} \leq 0.05$. NOE, natural outdoor environment.

Table S8 Association between NOE indicators and common somatic symptoms - excluding individual cities from analysis

\begin{tabular}{|c|c|c|c|c|}
\hline \multirow[t]{2}{*}{ NOE indicator } & \multicolumn{4}{|c|}{$\begin{array}{l}\text { Adjusted model } \\
\exp (\beta)(95 \% \mathrm{CI})\end{array}$} \\
\hline & $\begin{array}{c}\text { Exc. } \\
\text { Barcelona } \\
(n=2,511)\end{array}$ & $\begin{array}{c}\text { Exc. } \\
\text { Doetinchem } \\
(n=2,638)\end{array}$ & $\begin{array}{c}\text { Exc. } \\
\text { Kaunas } \\
(n=2,664)\end{array}$ & $\begin{array}{l}\text { Exc. Stoke- } \\
\text { on-Trent } \\
(n=2,630)\end{array}$ \\
\hline $\begin{array}{l}\text { Residential surrounding } \\
\text { greenness - } 100 \mathrm{~m} \text { buffer } \\
\text { (high vs low) }\end{array}$ & $\begin{array}{c}1.04 \\
(1.00-1.09)\end{array}$ & $\begin{array}{c}1.02 \\
(0.97-1.08)\end{array}$ & $\begin{array}{c}1.04 \\
(0.98-1.11)\end{array}$ & $\begin{array}{c}1.01 \\
(0.96-1.05)\end{array}$ \\
\hline $\begin{array}{l}\text { Residential surrounding } \\
\text { greenness - 300m buffer } \\
\text { (high vs low) }\end{array}$ & $\begin{array}{c}1.02 \\
(0.97-1.07)\end{array}$ & $\begin{array}{c}1.01 \\
(0.95-1.07)\end{array}$ & $\begin{array}{c}1.01 \\
(0.94-1.07)\end{array}$ & $\begin{array}{c}1.00 \\
(0.96-1.04)\end{array}$ \\
\hline $\begin{array}{l}\text { Residential surrounding } \\
\text { greenness - 500m buffer } \\
\text { (high vs low) }\end{array}$ & $\begin{array}{c}1.04 \\
(0.99-1.09)\end{array}$ & $\begin{array}{c}1.02 \\
(0.97-1.08)\end{array}$ & $\begin{array}{c}1.00 \\
(0.94-1.06)\end{array}$ & $\begin{array}{c}1.00 \\
(0.97-1.04)\end{array}$ \\
\hline $\begin{array}{l}\text { Presence of natural spaces } \\
-300 \mathrm{~m} \text { buffer }\end{array}$ & $\begin{array}{c}1.02 * \\
(1.00-1.05)\end{array}$ & $\begin{array}{c}1.04 \\
(1.00-1.08)\end{array}$ & $\begin{array}{c}1.03 * \\
(1.00-1.06)\end{array}$ & $\begin{array}{c}1.02 \\
(0.99-1.04)\end{array}$ \\
\hline $\begin{array}{l}\text { Presence of natural spaces } \\
-500 \mathrm{~m} \text { buffer }\end{array}$ & $\begin{array}{c}1.02 \\
(1.00-1.03)\end{array}$ & $\begin{array}{c}1.02 \\
(0.99-1.04)\end{array}$ & $\begin{array}{c}1.02 * \\
(1.00-1.04)\end{array}$ & $\begin{array}{c}1.01 \\
(0.99-1.02)\end{array}$ \\
\hline $\begin{array}{l}\text { Distance to nearest } \\
\text { natural space }\end{array}$ & $\begin{array}{c}1.00 \\
(0.9996- \\
1.00)\end{array}$ & $\begin{array}{c}1.00 \\
(0.9996-1.00)\end{array}$ & $\begin{array}{c}1.00 \\
(0.9995-1.00)\end{array}$ & $\begin{array}{c}1.00 \\
(0.9997-1.00)\end{array}$ \\
\hline Perceived amount of NOE & $\begin{array}{c}0.98 * * \\
(0.97-0.99)\end{array}$ & $\begin{array}{c}0.99 \\
(0.98-1.00)\end{array}$ & $\begin{array}{c}0.99 \\
(0.97-1.00)\end{array}$ & $\begin{array}{c}1.00 \\
(0.99-1.01)\end{array}$ \\
\hline $\begin{array}{l}\text { Time spent in NOE (high } \\
\text { vs low) }\end{array}$ & $\begin{array}{c}1.00 \\
(0.99-1.01)\end{array}$ & $\begin{array}{c}1.00 \\
(0.99-1.02)\end{array}$ & $\begin{array}{c}1.00 \\
(0.98-1.02)\end{array}$ & $\begin{array}{c}0.99 \\
(0.98-1.01)\end{array}$ \\
\hline Satisfaction with NOE & $\begin{array}{c}0.97 * * * \\
(0.96-0.98)\end{array}$ & $\begin{array}{c}0.97 * * * \\
(0.95-0.98)\end{array}$ & $\begin{array}{c}0.97 * * * \\
(0.96-0.98)\end{array}$ & $\begin{array}{c}0.98 * * \\
(0.97-1.00)\end{array}$ \\
\hline
\end{tabular}

Note: Mixed effects negative binomial models with random intercept for neighbourhood adjusted for age, gender, educational level, income, employment status, neighbourhood socioeconomic status, city, household composition, smoking status and dog ownership. $* p \leq 0.05 ; * * p<0.01 ; * * * p<0.001$. NOE, natural outdoor environment. 